\title{
How Do Fishing and Environmental Effects Propagate Among and Within Functional Groups?
}

\author{
Marie-Joëlle Rochet ${ }^{\mathrm{a}}{ }^{\text {*}}$, Jeremy S. Collie $^{\mathrm{b}}$, Verena M. Trenkel $^{\mathrm{a}}$ \\ a Ifremer, rue de l'île d'Yeu, BP 21105, 44311 Nantes cedex 3, France \\ ${ }^{b}$ Graduate School of Oceanography, University of Rhode Island, Narragansett Rhode Island 02882 \\ *: Corresponding author : Marie-Joëlle Rocher, email address : $\underline{\text { mirochet@ifremer.fr }}$
}

\begin{abstract}
:
Competition and predation can play different roles in mediating the influence of external pressures, such as fishing or environmental variations, on marine communities. Pressure effects propagate through food webs along predation links. These predator-prey interactions may result in trophic cascades, but they can be buffered by competitive interactions. We investigated these mechanisms by taking a functional-group approach. Are functional groups affected by external pressures in a predictable way? Within functional groups, do all species respond in the same way, or does competitive release allow for compensation among species? We constructed a simple community model, with functional groups connected by predation links. Loop analysis was used to make qualitative predictions of the changes in functional groups that might result through either direct or indirect effects from changes in pressures. Actual changes in biomass and average weight in functional groups were then tracked from fish trawl-survey data; compensation within groups was examined with dynamic factor analysis. This approach was applied to the Georges Bank, Bay of Biscay, and North Sea fish communities, which have been subject to different fishing regimes and have undergone environmental changes over the last decades. All three communities changed substantially. Compensation did not prevent impacts from propagating through the three food webs; rather, antagonistic pressures did. Community responses to perturbation were mostly determined by community structure and by fisheries selectivity with respect to both functional groups and species.
\end{abstract}




\section{Introduction}

Despite the widely held expectations that fishing impacts should propagate in marine communities through trophic links (Pope 1991, Hall et al. 2006, Andersen and Pedersen 2010, Rochet and Benoît 2012), field evidence is not easily found (Grubbs et al. 2011). One reason is that fishing is generally not selective across trophic levels; it takes both predators and their prey-indirect fishing impacts might be confounded with or counteracted by direct removals (Cox et al. 2002, Friedlander and deMartini 2002, Rochet et al. 2010). Fishing impacts are also confounded with environmental forcing and other stressors that interact in complex ways (Crain et al. 2008, Rochet et al. 2010). Another mechanism mitigating fishing impacts could be compensation among species. Compensation is the replacement of individuals or biomass of sensitive species, lost or depleted as a result of sustained perturbation, by individuals or biomass of less sensitive species, which increase to fill the gap (Gonzalez and Loreau 2009). Density compensation, which can maintain total community biomass when stressed species decline or even disappear, has been reported in a wide variety of communities (Gonzalez and Loreau 2009), including harvested fish assemblages (Dulvy et al. 2000, Shackell and Frank 2007, Auster and Link 2009). Compensation may arise when species interact negatively: the decrease in abundance of sensitive species removes the suppression of other species and allows them to increase. A large part of the theory of and empirical evidence for compensation deals with suppression caused by direct competition. In theory, compensation happens within groups of functionally similar species and may lessen or hinder trophic cascades when species replacements buffer direct effects of fishing. Such compensation is expected especially in the case of species-selective fishing, which takes only some species within a functional group.

Temperate fish communities have undergone changes in fishing pressure over the last few decades. Fishing effort increased with the industrialization of fishing fleets, then decreased as stronger regulations were imposed by management bodies. Changes in effort allocation among species groups might have occurred for both market and resource-availability reasons. Fishing has been reported to become decreasingly selective across functional groups as high trophic levels have been depleted (Essington et al. 2006). Environmental conditions have shifted or changed more gradually worldwide. In addition to directly influencing the state and functioning of marine ecosystems, environmental variability might also have altered population and community responses to fishing pressure (Planque et al. 2010).

We examined the possibility that species compensation resulting from within-group competition can prevent propagation of fishing and/or environmental perturbations along the predatory links and the possible relationship of such compensation to fishing selectivity. To do so, we examine empirically how functional groups and individual species responded to perturbations in exploited marine communities. We first predicted how perturbations should propagate among functional groups and examined the ways in which these predictions might help us understand the actual changes in functional groups. We then looked for any differences in species responses to known pressure changes within each functional group.

Our first step was to develop a rough index of fishing pressure per functional group. The second was to predict how fishing pressure and environmental changes might have propagated in the community. We used a qualitative approach whereby the qualitative 
consequences of perturbations, that is, changes in the amount of fishing pressure and/or primary production driven by the environment, were predicted by loop analysis of a simplified community model (Dambacher et al. 2003). Decadal sequences of important events in fishing pressure and primary production were used as input to this qualitative analysis, which predicted the decadal trends expected in functional-group biomass. As a third step, bottom-trawl survey data were used to determine whether actual changes in functional group and species biomass agreed with predicted trends. These survey data were also used in the fourth step, investigating long-term compensation within functional groups by dynamic factor analysis (Zuur et al. 2003). This multivariate technique extracts and identifies common trends from a set of time series. Several opposite, common trends shared by different species within a functional group would indicate compensation, whereas a single trend shared by most species would indicate synchrony.

The approach was applied to three North Atlantic temperate shelf-fish communities, Georges Bank, the Bay of Biscay, and the North Sea. All three have undergone important changes in both environmental and fishing pressures over the last decades. By comparing three systems that differ in the characteristics of productivity, dominant functional groups, and history and strength of fishing pressure, we hoped to gain general insights into propagation of pressures in communities.

\section{Materials and Methods}

\subsection{A Simple Community Model}

To investigate the relationships among fish functional groups and fleets, we formulated a simplified community model in which state variables were standing stocks (Fig. 1). The functional-group variables formed two coupled trophic chains, one pelagic and one benthodemersal. Most links were predator-prey links benefiting the predator and detrimental to the prey. The exception was benthos, which benefited from but was not expected to have a negative effect on living plankton, because suspension and deposit feeders are restricted to the bottom and eat dead plankton bodies. In this model, the functional groups did not compete directly-competition was indirect between groups feeding on common resources. Fisheries were grouped into three fleets: a pelagic fleet fishing for planktivores and pelagic piscivores; a demersal fleet fishing for demersal piscivores; and an invertebrate fleet fishing for crustaceans. Benthivores were taken, intentionally or as by-catch, by the second fleet, and benthos was affected by the fishing gears. The units for fleet variables were number of vessels or vessel power.

Some links in this model (the core model) might be weak (dotted lines in Fig. 1). Including or excluding these weak links generated model variants:

1. Reduced coupling when the predatory link between pelagic piscivores and demersal benthivores is weak or absent

2. Omnivory in the demersal food chain (that is, existence of a direct predatory link between demersal piscivores and benthos) 


\section{Combination of 1 and 2}

4. No bottom-up control from the second trophic level upwards; that is, no food limitation of piscivores (the positive links from benthivores and planktivores to piscivores were weak or absent)

5. On the time scale analyzed, community state and dynamics might not affect fleets: fleet dynamics depend little on the amount of fish available but do depend on external factors like market and fisheries regulations. In that case fleets would affect fish functional groups but would not benefit from their catch by increasing fleet size.

A qualitative analysis of the core model and its variants predicted the direction of changes in state-variable equilibrium that were expected from a permanent increase or decrease in (i) pelagic primary production or (ii) fishing fleet size. Consequences of simultaneous changes in several pressures could be predicted as well. This so called perturbation analysis was carried out without specification of the amounts of changes, and the results were qualitative-only the directions of change were predicted (see, e.g., Dambacher et al. 2009). A formalized qualitative analysis helps to resolve the conflicts between direct effects and feed-back loops that inevitably arise during attempts to predict consequences of pressure changes in networks. For each functional group, predicted changes included changes in both abundance and residence time. Residence time is the result of inflow (birth and growth) into and outflow (death) from a group. Increased inflow or outflow will lower average life expectancy and possibly individual size in the case of fish (Dambacher et al. 2009). The predicted directions of trends can be correct independent of any model parameter values, but under many other circumstances indeterminacy will be present in qualitative predictions, although a detailed analysis of the feedback structure can assign each prediction a probability scale for sign direction certainty (Dambacher et al. 2002). The predictions shown below are either certain, or have a certainty probability $>0.5$, across model variants listed above.

\subsection{Landings and Survey Data}

To characterize changes in fishing pressure, we combined landings and survey data. Community changes were investigated with indices estimated from trawl-survey data.

Georges Bank landings data were obtained from the Commercial Fisheries Database (Northeast Fisheries Science Center 2010). Landings data were downloaded from the International Council for the Exploration of the Sea catch-statistics website (http://www.ices.dk/fish/CATChSTATISTICS.asp) for the North Sea (January 2011) and Bay of Biscay (September 2011). All landings from the North Sea (that is Division IVa, b, c or IV nonspecified) were combined; the Kattegat and Skagerrak were excluded. Landings data from before 1974 were lacking for several countries, so earlier years were not used. For the Bay of Biscay, landings for Division VIIla, b, and d were combined; data from before 1988 and for 1999 and 2009 were not used because of incompleteness.

Fish community data are from stratified bottom trawl surveys described in Table 1 . To facilitate comparisons, we standardized all survey data to units per $\mathrm{km}^{2}$. Survey estimates were not corrected for catchability, because conversion factors are uncertain and only available for a few species in the North Sea (Fraser et al. 2007). For the North 
Sea, biomass was estimated from abundance-at-length data and length-weight relationships. The study was restricted to fish species, because invertebrates have not been consistently sampled across the time series in the North Sea and Bay of Biscay. To exclude species with high sampling variability and small contribution to biomass, we removed those species with low persistence (number of years present), low occurrence (among hauls), and/or low average abundance within each time-series; we used slightly different selection criteria to choose among the surveys to arrive at comparable numbers of species. Surveyed species were divided into four functional groups as described by Greenstreet et al. (1997) and Heath (2005a): planktivores, pelagic piscivores, demersal piscivores, and demersal benthivores. For each species, we considered the diets of adult fish and their predators to ensure that the classification was consistent with the model (Fig. 1). For Georges Bank, the groups used by Garrison and Link (2000) and Auster and Link (2009) were pooled into these same four functional groups (Appendix 1). In all three surveys, pelagic piscivores consisted of only two or three species that had not always been sampled consistently; this group was removed from the analyses. Although analyzing changes in the benthos functional group was desirable as well, the survey data were not deemed appropriate, as the few species that have been monitored consistently represent a minor fraction of benthos biomass. Therefore only three functional groups were examined: demersal piscivores (designated piscivores), planktivores, and demersal benthivores (designated benthivores). As with surveyed species, landed fish species were assigned to all four upper-level functional groups on the basis of the same classifications. Some landed species or higher-rank taxa could not be assigned to any group.

\subsection{Changes in Pressures}

To characterize decadal fishing-pressure changes, landings may be an appropriate proxy because catch is strongly correlated with fleet capacity in, e.g., the Bay of Biscay (Rochet et al. 2012), but landings alone may not reflect the relative pressures on functional groups, as they result from both resource availability and fishing intensity and selectivity. An index of exploitation by functional group was constructed by division of the landings summed across species within functional groups by the functional group biomass index from the surveys. This is a rough index, as some surveyed species were not present in the landings and the reverse. As the survey indices were not corrected for catchability, the index magnitude had no interpretable meaning and the values were standardized by the first value of the time series.

The main environmental drivers of primary production changes in the three communities were compiled from the literature, with a focus on the periods during which fish data were available. On the basis of this information, decadal categorical fishing pressure and primary production levels were identified for each community (Table 2).

\subsection{Trends in Functional Groups}

Because our study focused on the transfer of matter between functional groups and to fishing fleets, biomass was used as the metric for functional group abundance. Mean length is an appropriate metric of life expectancy at the population level (Trenkel et al. 2007, Dambacher et al. 2009). At the functional-group level, average individual length depends as much on relative abundances of species as on species-specific length structures; because we wanted a metric reflecting changes in size, not in species composition, population mean length averaged across species was more appropriate. 
As length was not consistently measured for all species in the Bay of Biscay survey, mean average weight was used. When available, mean average length and mean average weight were highly correlated in all three surveys.

Responsiveness of functional groups to pressure changes might vary depending on the type of perturbation and on the organisms' life expectancy, making the delay difficult to predict. Therefore smooth curves were fitted to functional-group biomass and mean weight to focus on decadal-scale trends. For this process, a lowess smoother that uses locally weighted polynomial regression was used with a 15-year span.

\subsection{Comparison of Model Predictions and Observations}

Trends in the smoothed time series within each decade were compared with model predictions by one-tailed Spearman rank correlation tests with the model predicted trend as null hypothesis and an $\alpha$ level of 0.1 ( $P$ values $\geq 0.9$ indicate support for the predicted trend, or "agreement"). Sensitivity of the conclusions to the smoother span value was analyzed by comparison of the numbers of agreements when the span varied from 7 to 30 years.

\subsection{Compensation within Functional Groups}

To determine whether compensation occurred within functional groups, we analyzed the dynamics of species within each functional group over the whole study period by dynamic factor analysis (DFA, Zuur et al. 2003). We used DFA to model the $N$ time series of species-specific annual biomass indices $\mathbf{y}_{t}$ in a given functional group according to

$\mathbf{y}_{t}=\mathbf{Z} \boldsymbol{\alpha}_{t}+\mathbf{e}_{t}$

where $\alpha_{t}$ are the values of $M$ common trends at year $t$, the $N \times M$ matrix $\mathbf{Z}$ contains the factor loadings, and $\mathbf{e}_{t}$ is a residual vector of size $N$. Factor loadings revealed which common trends are important to a particular species and which species contribute to each common trend. The number $M$ of common trends and the structure of the covariance matrix of the residuals $\mathbf{e}_{t}$ (either diagonal or symmetrical) were selected by comparison of models with the Akaike information criterion (AIC). Compensation was revealed by negatively correlated common trends, when different species had high positive loadings on each of these trends. Positive loadings of many species on the same common trend would identify synchrony within a functional group. We tested for compensation by one-tailed tests for negative Pearson correlations among common trends $\left(\mathrm{H}_{0}\right.$ : all pairwise correlations between trends are $\left.\geq 0\right)$ and for synchrony by onetailed binomial exact tests $\left(\mathrm{H}_{0}\right.$ : the proportion of species with positive loadings is $\left.>0.5\right)$, both with type I error risk $\alpha=0.1$. Functional groups exhibiting neither compensation nor synchrony were concluded to show independent dynamics.

The covariance structure of species-specific residuals $\mathbf{e}_{t}$ of biomass trends with respect to the common functional group trends tells how short-term species fluctuations within functional groups are related. A negative correlation is interpreted to indicate compensatory dynamics for the given species. Compensatory dynamics differ from compensation in being opposing responses to high-frequency environmental fluctuations rather than to sustained perturbation (Gonzalez and Loreau 2009). We examined the residual covariance structure of the model with the smallest AIC to identify short-term 
species dynamics as compensatory (nondiagonal covariance matrix with negative offdiagonal terms), synchronized (positive off-diagonal terms), or independent (diagonal covariance matrix).

DFA was carried out with the software Brodgar (http://www.brodgar.com) on normalized variables, so all species contributed equally to common trends irrespective of their contribution to the functional group biomass. As exploited marine communities and/or functional groups tend to be strongly dominated by one or a few species, whether a trend common to several species contributes to the group biomass trend depends on whether or not these species include the dominant species. To evaluate common trend contributions to the group trend, we also examined correlation of common trends with the smoothed trend in the pooled group biomass. This correlation analysis links back to how the common trends reflect the predicted consequences of changes in fishing and primary production.

\section{Results}

\subsection{Changes in Pressures}

On Georges Bank total landings showed a long-term sustained decrease (Fig. 2A). The proportion of each functional group in the landings varied substantially over 1963-2009. The contribution of nonclassified species, of which a large part is made up of skates, showed a long-term increase-skate catch is reported without species identification, even though species belong to different functional groups. Peaks in the catch of planktivores were ascribable to high catches of herring, mackerel, or both. The exploitation index decreased gradually for benthivores, whereas piscivores and planktivores showed parallel trends, except in the 1980s, during which benthivores seemed to undergo a period of higher fishing pressure (Fig. 2B). These trends were consistent with trends in estimated fishing mortality $(F)$ from stock assessments. Overall, the decadal categorical changes in pressures on Georges Bank can be summarized as follows: primary production increased steeply in the early 70 s and may have kept increasing more slowly over the subsequent decades, as suggested by indirect indices inferred from nutrient concentrations upstream from Georges Bank by Steele et al. (2007). Fishing pressure by the demersal fleet on benthivores was high in the 1960s, medium in the 70s, high in the 80s, and low after 1990 (Table 2). Fishing pressure on planktivores was high over the first time period until the late 1970s, then much lower (Table 2).

In the Bay of Biscay landings increased gradually, and the contributions of functional groups changed (Fig. 2C), but when scaled by functional group biomass in the survey, the exploitation index fluctuated widely and showed no clear trends, except perhaps a decline in fishing pressure on all three functional groups over the last decade (Fig. 2D). Stock assessments available for two species (hake and sole) are in agreement with this decline. Exploitation index relative levels did not change, suggesting that selectivity at the functional-group level has been constant. Fishing pressure on all three groups was high in the 1990s and lower in the 21st century; fishing pressure was assumed to have been already high before 1990, because French fishing-fleet size and power increased steeply from the 1950s and peaked in 1990 (Mesnil 2008; Table 2). Although water temperatures in the Bay of Biscay have increased steadily on the shelf $(<200 \mathrm{~m})$ since the 1970s (Michel et al. 2009), the only period with a somewhat higher primary 
production seems to be the early 1990s (Woillez et al. 2010). A stagnation in primary production would be consistent with the observation that the temperature increases in the North Atlantic (north of $30^{\circ}$ ) since the late 1970s have lead to an overall decrease in primary production (Gregg et al. 2003).

In the North Sea, total landings decreased gradually after the mid 1970 s and eventually dropped in the 21st century (Fig. 2E). In the late 1970s the decrease in landings occurred more or less equally across functional groups. Over the 1980s, piscivore landings declined, probably because of stock depletion. The exploitation index decreased consistently in the three functional groups over 1983-2000, suggesting that the fishing pressure decreased equally across functional groups; no substantial change occurred therefore in functional-group selectivity (Fig. 2F). This trend might have reversed over the last decade for planktivores and demersal piscivores, revealing an increase in fishing pressure ascribable more to resource rarefaction than to increased effort, but stock assessment results, available for eight species, suggest the reverse: a decline in $\mathrm{F}$ over the last decade. The fishing-pressure scenarios used for prediction assumed a single drop in the early 1980s common to the pelagic and demersal fleets (Table 2). Note that just landings, not exploitation index, were available for the 1970s. Several analyses of hydroclimatic variables and the continuous plankton recorder data suggest that a regime shift occurred around 1985-1988 in the North Sea (Reid et al. 2001, Beaugrand 2004). Another regime shift in the plankton community in the late 1990s might have been the major cause of low recruitment to several small pelagic forage fish stocks during that period (Payne et al. 2009, van Deurs et al. 2009).

Note that all three functional groups incurred similar levels of fishing pressure as measured by the exploitation index in the Bay of Biscay and North Sea, whereas more contrast was apparent on Georges Bank, suggesting that fishing was more selective among functional groups on the latter. Further, in the Bay of Biscay and North Sea, fishing pressure per functional group fluctuated in broadly parallel ways, whereas the group receiving the highest fishing pressure on Georges Bank showed clearer changes. Therefore fishing selectivity among functional groups changed more on Georges Bank than in the northeast Atlantic.

\subsection{Model Trend Predictions}

Simultaneous changes in several pressures (several fishing fleets and/or primary production) and certain model variants led to ambiguous predictions in several instances (Table 2). On Georges Bank, pressures were not counteracting each other, and a consistent set of trends could be predicted for biomass and life expectancy for all three functional groups (Table 2). For example, the drop in the demersal fleet pressure, increase in the pelagic fleet, and increase in primary production that occurred by the end of the 1960s were predicted to result in increased biomass for benthivores and piscivores and decreased life expectancy for piscivores and planktivores (Table 2). In the Bay of Biscay, on the assumption that primary production remained high in the 2000s, biomass was predicted to have increased and life expectancy decreased in all three functional groups during the 1990s; piscivore biomass was predicted to have kept increasing while planktivore biomass should have decreased in the 2000s (Table 2). In the North Sea, the consequences of the decrease in the 1980s in both pelagic and demersal fishing fleets could not be predicted for all groups, as it made pressure levels change in the same direction for both predators (demersal piscivores) and their prey (benthivores), creating counteracting indirect effects. A complete set of trends in 
biomass was predicted if fishing pressure for the 1990s and 2000s was assumed to have remained constant after dropping in the 1980s (Table 2).

\subsection{Trends in Functional Groups}

Functional groups exhibited many changes in survey-based estimates of both biomass and average weight in all three ecosystems (Fig. 3). On Georges Bank, planktivore biomass was found to be one order of magnitude lower than those of benthivores and piscivores, whereas in the North Sea, benthivores were the low-biomass group. The Bay of Biscay was strongly dominated by planktivores, and both demersal groups had much lower biomasses (Fig. 3).

On Georges Bank, benthivore biomass exhibited a W-shaped trend, which was overall consistent with the pressure trends based model predictions in Table 2. The observed decrease in the 1960s could have been the result of an increase in fishing pressure before the 1960s (for which we have no data). Piscivores increased, decreased around the 1990s, and increased again; this pattern seems to follow closely the changes in the demersal fishing fleet pressure, although changes in trend direction did not coincide with decades, resulting in disagreement with model predictions (Table 2). Planktivore biomass peaked in the late 1990s, in response to both bottom-up and top-down pressures-the initial increase resulted from increasing primary production despite the increase in predation mortality expected from the increasing biomass of piscivores; the steeper increase until 1995 could be a combined consequence of changes in both fleets and primary production; and the ultimate decrease could have been a potential outcome of increasing pressure by predators resulting both from decreased demersal fishing pressure and propagation of increased primary production. Again observed changes in trend directions did not coincide with decades and therefore disagreed with predictions (Table 2). Mean average weight decreased in the three functional groups in a series of waves. For benthivores and planktivores, these waves were shifted a decade earlier or later than predictions (Table 2).

In the Bay of Biscay, biomass increased in all three functional groups; this increase started later in piscivores possibly because of the delay in bottom-up propagation of increased primary production and increased fishing pressure. Mean average weight generally decreased in the 90 s but increased in benthivores in the 21st century, in agreement with the predicted response to changes in primary production (Table 2).

In the North Sea, piscivore biomass fluctuated without trend until the late 1990s; it did not seem to respond as predicted to decreased fishing pressure. Planktivores, which the model predicted to decrease because of increased predation by piscivores, increased instead. Subsequent changes in biomass and mean average weight of both groups were consistent with predicted consequences of changes in primary production (Table 2). Benthivore biomass overall increased with a brief decrease in the early 1990s, none of which was predicted by the model. In all three functional groups the Ushaped trends in mean average weight were consistent with the predicted consequences of changes in primary production, except for planktivores which decreased monotonically (Table 2, Fig. 3).

Overall, the complete sequence of predicted decadal trends in functional-group biomass was in agreement with trends in survey data in three out of nine groups, whereas predicted decadal trends in life expectancy were correct for six groups out of eight 
(Table 3). For six other groups, predicted trends were consistent with the data only for some decades (e.g., the model correctly predicted that planktivore biomass in the North Sea would increase in the 1990s and subsequently decrease but failed to predict the initial increase in the 1980s). Overall, out of the 41 predictions in Table 2, $25(61 \%)$ turned out to be in agreement with the survey data. Recall that ambiguity precluded unambiguous predictions in 13 cases, which were therefore not considered in the comparison (Table 2). The results are sensitive to the span used for smoothing the data (Appendix 2). The number of agreements between smoothed time-series and model predictions increased with the smoother time span on Georges Bank and in the Bay of Biscay but peaked at 15 years in the North Sea (Appendix 2).

\subsection{Compensation within Functional Groups}

Functional groups and ecosystems varied widely in the number of common time trends within groups identified by DFA, which ranged from 1 to 6 . Among the models with smallest AIC, all but two had diagonal error-covariance matrices-that is, no correlation structure was identifiable in the residuals. The exceptions were the Bay of Biscay benthivores and piscivores, both of which had positive nondiagonal error-covariance matrices, indicating synchronized short-term dynamics among the species of these groups.

\subsubsection{Georges Bank Common Trends}

For Georges Bank benthivore species, six common time trends were identified. Trend 1, shared by 12 of the 23 species, was independent of the pooled functional-group biomass trend (Fig. 4, Appendix 3) but tracked decadal fluctuations in demersal fishing pressure in Table 2. Trend 2 was strongly correlated with the overall functional group biomass trend. Haddock and yellowtail flounder, which have high loadings on trend 2, are both fishery target species that have declined and recovered during the study period-hence the $U$ shape. The other four benthivore trends were shared only by a few species (Fig. 4) and appeared to be relatively independent of each other. Because none of the six common trends was shared by more than half of the group species, we concluded that benthivores showed no significant synchrony. On the contrary, negative correlations of trend 1 with trends 2, 5, and 6 (Appendix 3) indicated compensation (Table 3).

Piscivore species on Georges Bank had three common trends (Fig. 4). Trend 1 was common to eight of the 14 species and opposite to the group biomass trend (Appendix 3 ). This declining trend in several piscivores could be a shared response to interdecadal fishing-pressure decrease but with a recovery slower than that of benthivore species. The two dominant piscivore species, spiny dogfish and winter skate, each had a high loading on the other two trends (Fig. 4), which were negatively correlated with trend 1 (Appendix 3), suggesting compensation between species within the piscivore group (Table 3). In this functional group, target groundfish species that declined were replaced first by winter skate and then by spiny dogfish (Fig. 5).

Among planktivore species, three trends were common to one to three species each (Fig. 4) and were negatively correlated (Appendix 3), indicating compensation within the group (Table 3). The dominant target species herring and mackerel made high contributions to trend 3 , which was therefore highly correlated with the pooled group 
trend (Appendix 3). Within this group, some species decreased whereas herring and mackerel increased.

\subsubsection{Bay of Biscay Common Trends}

The Bay of Biscay benthivore species had two common trends (Fig. 6), which were positively correlated. Trend 1 was shared by eight species of the 21 in the group and was highly correlated with the group biomass (Appendix 3 ). The initial decrease of trend 1 may be a response to strong fishing pressure in the first decades of the study period, although none of these species is a primary target of fisheries. Trend 2 was shared by minor contributors to the group biomass and might be a response to interdecadal changes in primary production. The two dominant species in this group, bib and poor cod, were weakly represented on trends 1 and 2. Bib decreased and was to a large extent replaced by catshark (Fig. 5). Because neither synchrony nor compensation was significant in this group, benthivore species were noted to have had independent dynamics (Table 3).

Among piscivores, trend 1 was shared by 10 of 13 species (Fig. 6), denoting significant synchrony within the group (trend common to more than half of the species, $P=0.046$ ). Trend 1, increasing, included the major group contributors and was thus highly correlated with the group biomass trend (Appendix 3), in agreement with response to changes in demersal fishing pressure and primary production. Trend 2 encapsulated the initial decrease in two dominant species, hake and whiting, as well as megrim and plaice, all of which are fisheries targets-this trend might be a response to changes in fishing pressure.

In Bay of Biscay planktivore species, trend 2, shared by seven of 13 species (Fig. 6), was positively correlated with the group trend (Appendix 3), because the three most abundant species had positive loadings. Trend 1 isolated two peaks occurring early in the series for a few minor functional group biomass contributors. Trends 1 and 2 were negatively correlated, suggesting compensation, also visible from the species composition: mackerel expanded while horse mackerel and blue whiting became less dominant (Fig. 5, Table 3).

\subsubsection{North Sea Common Trends}

Three common trends were identified among North Sea benthivore species (Fig. 7). Trend 1 was common to almost all species of this group, indicating synchrony $(P=$ 0.0004 , Table 3 ). This trend was slowly increasing and positively correlated with the pooled group biomass (Appendix 3)-potentially a response to the observed decreasing fishing pressure on benthivores. Trend 2 showed a reinforced increase exhibited by many species in the group, again consistent with decreasing fishing pressure. Trend 3 exhibited independent medium-term fluctuations that reflected the predicted effect of increased primary production on this group (Table 2).

For piscivore species in the North Sea, of which most are targets of demersal fisheries, four common trends were identified (Fig. 7). None was shared by a majority of species. Trend 1, increasing, was shared by a number of low contributors to the group biomass (Appendix 3). Trends 2 to 4 were each led by a dominant species in the group, 
respectively whiting, haddock, and cod. Trends 2 and 4 were decreasing; the decreases began at different times, all earlier than predicted by the model, that is, before 2000 (Table 2). Trend 3, dominated by haddock, conformed most closely with predictions in Table 2, except for the initial increase. Significant negative correlations between common trends provided evidence for compensation within the piscivore group (Table 3 ); compensation was most obvious in the replacement of cod by grey gurnard (Species 3 and 4 in Fig. 5).

The single common trend identified in North Sea planktivore species was dome-shaped (Fig. 7) and positively correlated with the group biomass trend $(R=0.63)$. This trend, shared by six species, seemed to represent the predicted response to decreased pelagic fishing pressure and interdecadal changes in primary production (Table 2), but herring, the dominant species in the planktivore group, which was largely responsible for the group decrease over the last decade, had a low loading on this trend. Obviously the loss of herring was not compensated for by other species. Because evidence supports either synchrony or compensation, species dynamics in this groups were termed independent (Table 3).

\section{Discussion}

We did not find evidence for fishing through the food web" (Essington et al. 2006) in any of the three ecosystems. Fishing through the food web would mean that an increasing number of functional groups would incur high fishing pressure-fishing would become less selective across functional groups. Changes in selectivity at the functional-group level were found only on Georges Bank, which had the longest study period, and they consisted more of switches between successive target groups than of a broadening of the fished spectrum.

A difference between Georges Bank and the northeast Atlantic ecosystems is that most species are fishery targets in the latter, whereas fishing is more selective with respect to species on the former. For example, fishing pressure on spiny dogfish was initially low but increased in the 1990s when other target species were depleted on Georges Bank. In contrast, all species were targets long ago in the piscivore groups in the Bay of Biscay and North Sea. Although not all species were actual targets in the benthivore and planktivore groups in these ecosystems, many were taken as by-catch (and often landed) as these multispecies fisheries deploy a range of gears, most of which have low species and size selectivity. We expected to see more compensation within the functional groups in which the pressure changes differentially affected species than in the group as a whole. Therefore, because fishing is more selective within functional groups on Georges Bank, we were not surprised to see more compensation there than in the other two communities.

We did not, however, find that compensation within functional groups hindered propagation of pressures across groups, as suggested, e.g., by Auster and Link (2009). All functional groups in all three ecosystems changed in biomass, whether their species compositions changed or not. Thus compensation among species within functional groups did not buffer changes in pooled group biomass. Rather, compensation within a functional group seemed to be independent of whether the group had changed as predicted from the propagation of observed changes in pressures in the model community (Table 3). 
Because both interspecific competition within groups and propagation along predation links determine species response to pressures, neither type of interaction can be said to be more important in the studied marine communities. Below we discuss in further detail how pressures propagated across the community and the relationship of this process to community structure; how species responses compensated for each other and whether we can determine the cause of the absence of compensatory dynamics; and finally how methodological choices affected the results.

\subsection{Propagation of Pressures among Functional Groups}

Direct effects of pressures on the functional groups receiving them were found in all three ecosystems. Indirect effects propagated along predation links were also found in two instances. The decrease in planktivore biomass on Georges Bank in the 1990s and 2000s can be interpreted as a consequence of decreased fishing pressure on their predators. Piscivore biomass decreased in the North Sea in the 2000s, in agreement with decreased food for their prey. In the other instances, the predicted indirect effects were inconsistent with the data, possibly because they were counteracted by concomitant changes in other pressures. For example, benthivore biomass increased in the North Sea in the 2000s, when it was expected to decrease because of decreased primary production, perhaps because at the same time this group was subject to decreased fishing pressure.

In the North Sea and Bay of Biscay, the expected effects of changes in fishing pressure were generally not found in the time trends of biomass indices, possibly because the simultaneous variations in fishing pressure on each functional group, and in primary production, counteracted each other. In contrast, on Georges Bank the variations in primary production and fishing pressure were synergistic rather than antagonistic, at least for the demersal groups, resulting in consistent predictions and evidence. These findings suggest that multiple pressures complicate propagation across the communitywe concur with Planque et al. (2010) that community responses to environmental variability and fishing interact and therefore can hardly be -disentangled."

\subsection{Contrasted Community Structures}

The relative abundances of functional groups were contrasted across ecosystems: the Bay of Biscay was dominated by planktivores, which had low biomass on Georges Bank, whereas benthivores had low biomass in the North Sea. The latter result was in agreement with the relative magnitude of known estimates of functional group production (Heath 2005a). This pattern might be only partly explained by the difference in survey gears-the 1-m difference in vertical opening used on Georges Bank seems unlikely to explain differences in estimated pelagic biomass of one (for the North Sea) or two (for Bay of Biscay) orders of magnitude, and footrope equipment seemed to be comparable in all three gears. In a bottom-up perspective, we might infer from the contrasted biomass distribution that piscivores depended on benthivores on Georges Bank, planktivores in the Bay of Biscay, and both in the North Sea. The examination of time trends tells a complementary story. On Georges Bank, trends in piscivores followed those in benthivores and were opposite to those in planktivores, suggesting a strong bottom-up link from benthivores to piscivores and top-down link from piscivores to planktivores. In contrast in the North Sea piscivores suffered from the decrease in planktivores, and benthivores seemed to benefit from the decrease in their predators, suggesting that the strong bottom-up link is from planktivores to piscivores and the top- 
down link from piscivores to benthivores, consistent with previous findings (Heath 2005a). In the Bay of Biscay piscivore dynamics seemed to follow benthivores but had no impact on planktivores, a result that outlines, as on Georges Bank, the bottom-up link from benthivores to piscivores and is also consistent with previous findings (Heath 2005b).

\subsection{Compensation within Functional Groups}

Compensation within groups resulting from alleviated interspecific competition was found in all three functional groups on Georges Bank but in only one in the Bay of Biscay and North Sea. Our results are consistent with previous studies of the Georges Bank fish community, which documented the replacement of demersal species by elasmobranchs (Fogarty and Murawski 1998). Species compensation within functional groups has previously been found on the adjacent Scotian Shelf (Shackell and Frank 2007) and across the continental shelf of the northeast US, which includes Georges Bank (Auster and Link 2009). Compensation may be rare in groups with low species diversity or functional redundancy when no species is available to replace a depleted species. The insurance hypothesis states that biodiversity and redundancy provide an insurance against loss of species (Gonzalez and Loreau 2009), but we found no relationship between the occurrence of compensation in a group and either species richness or evenness within this group (Table 3). Compensation happened in the groups with the highest and lowest richnesses (Georges Bank benthivores and planktivores), and synchrony was found in the groups with the highest and lowest evennesses (Bay of Biscay piscivores and North Sea benthivores, Table 3). Our study therefore provides little support for the insurance hypothesis. Rather, weaker evidence for compensation in the northeast Atlantic case studies might result from the lower fishing selectivity across and within functional groups. Indeed we expected to see more compensation on Georges Bank because species within a group undergo more contrasted levels of fishing pressure there than in the Bay of Biscay and North Sea.

\subsection{Short-Term Compensatory Dynamics}

We found no evidence for short-term compensatory dynamics within functional groups. On the contrary, DFA residuals were independent or even positively correlated (synchronized). Positive correlations in the residuals may be caused by measurement errors. Interannual variations in abundance indices were partly explained by survey conditions such as wind conditions and survey design: starting date, number of hauls close to the coast, distribution of hauls (Poulard and Trenkel 2007). These year effects of catchability have been demonstrated in the Bay of Biscay survey for benthic and demersal species but not for pelagic species, consistent with the status of planktivores in the present study as the only Bay of Biscay functional group with a diagonal covariance matrix. Annual catchability variations could even mean that survey data are not appropriate for the study of compensatory dynamics. In the worst case, survey catchability effects would potentially conceal compensatory dynamics. One way forward might be to model observation errors explicitly. Multivariate state-space models are being developed as means of measuring species covariation while accounting for measurement errors (Ives et al. 2003). 


\subsection{Impact of Methodological Choices}

Discrepancies between model predictions and survey evidence may result from (i) incorrect assumptions about the direction and timing of pressure changes, (ii) incorrect model and thus predictions of pressure propagation, or (iii) inappropriate interpretation of the signal in the data.

The exploitation index we developed is rough. Landings and surveys differ in the species composition of functional groups, and the index does not take account of differential survey catchability of species, which might generate spurious trends because species composition changed in several groups over the study period. Further, landings consist of larger individuals than surveys, which often aim at recruits and therefore younger individuals; small fish caught and discarded by commercial fleets are not accounted for in landings. On Georges Bank and in the Bay of Biscay, available stock assessments were in agreement with the exploitation index, but in the North Sea they were not. Stock assessments may provide too restricted a picture of actual fishing pressure because they focus on a short list of target species. Whether this was the case, or the exploitation index was flawed for any of the reasons above, deserves further investigation. At the other end, the literature review did not always provide a clear understanding of decadal changes in primary production that could be easily translated for modeling. Incomplete knowledge of decadal pressure changes might explain why we failed to predict all observed functional group trends accurately.

Even if the pressure indices were correct, many model predictions of directions of change were not certain consequences of the network structure but likely outcomes with a reasonably high level of certainty. The realized outcome might differ from the most likely prediction in any particular situation if direct and indirect effects antagonize. Relying on predictions that are robust across several model variants alleviates this weakness, but does not remove it completely. Further, the qualitative analysis predicts directions from an assumed equilibrium state to the next equilibrium state. Ecosystems, as they undergo the influence of changing pressures, are generally not at equilibrium; because starting states are not fully understood, the qualitative prediction of directions of change might be wrong. Furthermore, transient dynamics can be complex and are not always a monotonic shift from an equilibrium state to the next.

Finally, the moderate agreement between model predictions and survey indices also resulted from some arbitrary settings in the method. The results were sensitive to the span used to smooth the functional-group metric time series: a longer span generally improved the agreement with model predictions, especially on Georges Bank. One explanation is that larger fish size might slow down the translation of both direct and indirect effects in this ecosystem. The arbitrary cutting of the time series into decades can also generate disagreements when actual changes in trend direction are shifted by a few years rather than by decades.

\subsection{Is a Functional-Group Approach Relevant}

Our findings suggest that community responses to perturbation are mostly determined by (i) community structure and (ii) whether pressures are synergistic or antagonistic. Community structure results both from environmental settings and from the legacy of historical fisheries. For example, the strong dominance by planktivores in the Bay of Biscay, which makes this ecosystem more sensitive to bottom-up than to top-down 
forcing, is at least partly a consequence of fishing impacts on piscivores such as large elasmobranchs and blackspot sea bream over the past decades and centuries (Quéro and Cendrero 1996, Lorance 2011). Less selective fisheries seem to create antagonistic pressures, the impacts of which are less predictable.

When pressures act on species rather than groups, why would a functional group approach be useful? Our results suggested that functional groups are still relevant to examination of the propagation of pressures. Indeed, the agreement between model predictions and observed time trends, which was found for three different ecosystems, suggests that our attempt to structure the community reflected its functioning at least to some extent and therefore that functional groups are useful for elucidating the dynamics of exploited fish communities. Functional groups reduce the complexity, allowing models to be developed and fitted. Other studies examined various ways of grouping species in attempts to separate climate- and fishing-induced changes in the North Sea; e.g., species were grouped by trophic level or biogeographic affinity (Engelhard et al. 2011, ter Hofstede and Rijnsdorp 2011). The advantage of the functional-group approach we used is that it places species groups into a conceptual model, which is meant to integrate the influence of the multiple pressures that inevitably act upon an exploited community, rather than to distinguish them.

Functional groups can also have practical implications. On the basis of their finding that functional groups were more resilient than species because of species compensation, Auster and Link (2009) proposed that total allowable catch could be set at the functionalgroup level rather than species level. This proposal seems to be more suitable to Georges Bank than to the European ecosystems, where lower selectivity both within and across functional groups resulted in lower compensation within groups and less predictable propagation of pressures across functional groups. Less selective fisheries might be more difficult to manage, because exploiting a wider range of species seems more likely to result in unpredictable dynamics at the species level, whereas in most market places the demand is for particular species, not functional groups. Therefore exploiting communities in a less selective way may require more flexible markets. Paradoxically enough, setting total allowable catches at the functional-group level seems to be advisable, either when just a few species within each functional group are targets or when the species within a functional group are interchangeable on the market.

\section{Acknowledgments}

We thank Richard Bell and two anonymous referees for comments on previous versions of the manuscript. This contribution received financial support from the EU FP7 grant FACTS (Forage Fish Interactions), grant agreement no. 244966, and the Pew Charitable Trusts. JC acknowledges the NSF award OCE0814592. The opinions expressed are those of the authors and do not necessarily reflect the views of funding agencies. 


\section{Literature Cited}

Andersen KH, Pedersen M. 2010. Damped trophic cascades driven by fishing in model marine ecosystems. Proc R Soc B Biol Sci. 277:795-802.

Auster PJ, Link JS. 2009. Compensation and recovery of feeding guilds in a northwest Atlantic shelf fish community. Mar Ecol Prog Ser. 382:163-172.

Azarovitz TR. 1981. A brief historical review of the Woods Hole Laboratory trawl survey time series. In: Doubleday WG, Rivard D, editors. Bottom trawl surveys. Canadian Special Publication of Fisheries and Aquatic Science 58. Ottawa: Department of Fisheries and Oceans. p. 62-67.

Beaugrand G. 2004. The North Sea regime shift: evidence, causes, mechanisms and consequences. Prog. Oceanogr. 60:245-262.

Cox SP, Essington TE, Kitchell JF, Martell SJD, Walters CJ, Boggs C, Kaplan I. 2002. Reconstructing ecosystem dynamics in the central Pacific Ocean, 1952-1998. II. A preliminary assessment of the trophic impacts of fishing and effects on tuna dynamics. Can J Fish Aquat Sci. 59:1736-1747.

Crain CM, Kroeker K, Halpern BS. 2008. Interactive and cumulative effects of multiple human stressors in marine systems. Ecol Lett. 11:1304-1315.

Dambacher JM, Gaughan DJ, Rochet MJ, Rossignol PA, Trenkel VM. 2009. Qualitative modelling and indicators of exploited ecosystems. Fish Fish. 10:305-322.

Dambacher JM, Li HW, Rossignol PA. 2002. Relevance of community structure in assessing indeterminacy of ecological predictions. Ecology 83:1372-1385.

Dambacher JM, Li HW, Rossignol PA. 2003. Qualitative predictions in model ecosystems. Ecol Model. 161:79-93.

Dulvy NK, Metcalfe JD, Glanville J, Pawson MG, Reynolds JD. 2000. Fishery stability, local extinctions, and shifts in community structure in skates. Conserv Biol. 14:283-293.

Engelhard GH, Ellis JR, Payne MR, ter Hofstede R, Pinnegar JK. 2011. Ecotypes as a concept for exploring responses to climate change in fish assemblages. ICES $\mathrm{J}$ Mar Sci. 68:580-591.

Essington TE, Beaudreau AH, Wiedenmann J. 2006. Fishing through marine food webs. Proc Natl Acad Sci USA. 103:3171-3175.

Fogarty MJ, Murawski SA. 1998. Large-scale disturbance and the structure of marine systems: fishing impacts on Georges Banks. Ecol Appl. 8:S6-S22.

Fraser HM, Greenstreet SPR, Piet GJ. 2007. Taking account of catchability in groundfish survey trawls: implications for estimating demersal fish biomass. ICES J Mar Sci. 64:1800-1819.

Friedlander AM, deMartini EE. 2002. Contrasts in density, size, and biomass of reef fishes between the northwestern and the main Hawaiian islands: the effects of fishing down apex predators. Mar Ecol Prog Ser. 230:253-264.

Garrison LP, Link J. 2000. Dietary guild structure of the fish community in the northeast United States continental shelf ecosystem. Mar Ecol Prog Ser. 202:231-240.

Gonzalez A, Loreau M. 2009. The causes and consequences of compensatory dynamics in ecological communities. Annu Rev Ecol Evol Syst. 40:393-414.

Greenstreet SPR, Bryant AD, Broekhuizen N, Hall SJ, Heath MR. 1997. Seasonal variation in the consumption of food by fish in the North Sea and implications for food web dynamics. ICES J Mar Sci. 54:243-266.

Gregg WW, Conkright ME, Ginoux P, O'Reilly JE, Casey NW. 2003. Ocean primary production and climate: global decadal changes. Geophys Res Lett. 30:1809.

Grubbs RD, Carlson JK, Romine JG, Curtis T, McElroy D. 2011. Save the bay, eat a ray: a purported trophic cascade mediated by declines in large shark populations 
and the consequences of applying simplistic models to complex ecosystems. Oral pressentation, 8th Florida State University William R. and Lenore Mote International Symposium, Sarasota, Florida, 8-10 November 2011.

Hall SJ, Collie JS, Duplisea DE, Jennings S, Bravington M, Link J. 2006. A lengthbased multispecies model for evaluating community responses to fishing. Can $\mathrm{J}$ Fish Aquat Sci. 63:1344-1359.

Heath MR. 2005a. Changes in the structure and function of the North Sea fish foodweb, 1973-2000, and the impacts of fishing and climate. ICES J Mar Sci. 62:847-868.

Heath MR. 2005b. Regional variability in the trophic requirements of shelf sea fisheries in the Northeast Atlantic, 1973-2000. ICES J Mar Sci. 62:1233-1244.

ICES (International Council for the Exploration of the Sea). 1991. Report of the study group on the coordination of bottom trawl surveys in sub-areas VI, VII and VIII and division IXa. ICES Council Meeting 1991/G. p. 13.

ICES (International Council for the Exploration of the Sea). 1996. Manual for the International Bottom Trawl Surveys. Addendum to ICES Council Meeting 1996/H. p. 1.

Ives AR, Dennis B, Cottingham KL, Carpenter SR. 2003. Estimating community stability and ecological interactions from time-series data. Ecol Monogr. 73:301-330.

Lorance P. 2011. History and dynamics of the overexploitation of the blackspot sea bream (Pagellus bogaraveo) in the Bay of Biscay. ICES J Mar Sci. 68:290-301.

Mesnil B. 2008. Public-aided crises in the French fishing sector. Ocean Coast Manage. 51:689-700.

Michel S, Vandermeirsch F, Lorance P. 2009. Evolution of upper layer temperature in the Bay of Biscay during the last 40 years. Aquat Living Resour. 22:447-461.

Northeast Fisheries Science Center. 2010. Commercial fisheries database/landings, 1963-2009. Woods Hole, Massachusetts: National Marine Fisheries Service.

Payne MR, Hatfield EMC, Dickey-Collas M, Falkenhaug T, Gallego A, Gröger J, Licandro P, Llope M, Munk P, Röckmann C, et al. 2009. Recruitment in a changing environment: the 2000s North Sea herring recruitment failure. ICES J Mar Sci. 66:272-277.

Planque B, Fromentin JM, Cury P, Drinkwater KF, Jennings S, Perry RI, Kifani S. 2010. How does fishing alter marine populations and ecosystems sensitivity to climate? J Mar Syst. 79:403-417.

Pope JG. 1991. The ICES multispecies assessment working group: evolution, insights, and future problems. ICES Mar Sci Symp. 193:22-33.

Poulard J-C, Trenkel VM. 2007. Do survey design and wind conditions influence survey indices? Can J Fish Aquat Sci. 64:1551-1562.

Quéro J-C, Cendrero O. 1996. Incidence de la pêche sur la biodiversité ichtyologique marine: le bassin d'Arcachon et le plateau continental Sud Gascogne. Cybium. 20:323-356.

Reid PC, Borges MF, Svendsen E. 2001. A regime shift in the North Sea circa 1988 linked to changes in the North Sea horse mackerel fishery. Fish Res. 50:163171.

Rochet MJ, Benoît E. 2012. Fishing destabilizes the biomass flow in the marine size spectrum. Proc R Soc B Biol Sci. 279:284-292.

Rochet MJ, Daurès F, Trenkel VM. 2012. Capacity management, not stock status or economics, drives fleet dynamics in the Bay of Biscay ecosystem on a decadal time scale. Can J Fish Aquat Sci. 69:695-710.

Rochet MJ, Trenkel VM, Carpentier A, Coppin F, Gil de Sola L, Léauté J-P, Mahé J-C, Maiorano P, Mannini A, Murenu M, et al. 2010. Do changes in environmental 
pressures impact marine communities? An empirical assessment. J Appl Ecol. 47:741-750.

Shackell NL, Frank KT. 2007. Compensation in exploited marine fish communities on the Scotian Shelf, Canada. Mar Ecol Prog Ser. 336:235-247.

Steele JH, Collie JS, Bisagni JJ, Gifford DJ, Fogarty MJ, Link JS, Sullivan BK, Sieracki ME, Beet AR, Mountain DG, et al. 2007. Balancing end-to-end budgets of the Georges Bank ecosystem. Prog Oceanogr. 74:423-448.

ter Hofstede R, Rijnsdorp AD. 2011. Comparing demersal fish assemblages between periods of contrasting climate and fishing pressure. ICES J Mar Sci. 68:11891198.

Trenkel VM, Rochet M-J, Mesnil B. 2007. From model-based prescriptive advice to indicator-based interactive advice. ICES J Mar Sci. 64:768-774.

van Deurs M, van Hal R, Tomczak MT, Jónasdóttir SH, Dolmer P. 2009. Recruitment of lesser sandeel Ammodytes marinus in relation to density dependence and zooplankton composition. Mar Ecol Prog Ser. 381:249-258.

Woillez M, Petitgas P, Huret M, Struski C, Léger F. 2010. Statistical monitoring of spatial patterns of environmental indices for integrated ecosystem assessment: application to the Bay of Biscay pelagic zone. Prog Oceanogr. 87:83-93.

Zuur AF, Tuck ID, Bailey N. 2003. Dynamic factor analysis to estimate common trends in fisheries time series. Can J Fish Aquat Sci. 60:542-552. 


\section{Appendix}

Appendix 1. Species lists. Common and Latin names of species within each functional group; rank is the biomass rank of the species within the functional group.

\subsection{Georges Bank}

\begin{tabular}{l} 
Common Name \\
\hline Haddock \\
Little skate \\
Longhorn sculpin \\
Yellowtail flounder \\
Winter flounder \\
Red hake \\
Thorny skate \\
Barndoor skate \\
Fourspot flounder \\
Smooth dogfish \\
American plaice \\
Ocean pout \\
Scup \\
Witch flounder \\
Atlantic wolffish \\
Cusk \\
Northern sea robin \\
Blackbelly rosefish \\
Moustache sculpin \\
Gulf Stream flounder \\
Black sea bass \\
Fourbeard rockling \\
Alligatorfish \\
Spiny dogfish \\
Winter skate \\
Atlantic cod \\
Silver hake \\
Pollock \\
Goosefish
\end{tabular}

\begin{tabular}{|c|c|c|}
\hline Latin name & Functional group & Rank \\
\hline Melanogrammus aeglefinus (Linnaeus, 1758) & Benthivore & 1 \\
\hline Leucoraja erinacea (Mitchill, 1825) & Benthivore & 2 \\
\hline Myoxocephalus octodecemspinosus (Mitchill, 1814) & Benthivore & 3 \\
\hline Limanda ferruginea (Storer, 1839) & Benthivore & 4 \\
\hline Pseudopleuronectes americanus (Walbaum, 1792) & Benthivore & 5 \\
\hline Urophycis chuss (Walbaum, 1792) & Benthivore & 6 \\
\hline Amblyraja radiata (Donovan, 1808) & Benthivore & 7 \\
\hline Dipturus laevis (Mitchill, 1818) & Benthivore & 8 \\
\hline Paralichthys oblongus (Mitchill, 1815) & Benthivore & 9 \\
\hline Mustelus canis (Mitchill, 1815) & Benthivore & 10 \\
\hline Hippoglossoides platessoides (Fabricius, 1780) & Benthivore & 11 \\
\hline Zoarces americanus (Bloch \& Schneider, 1801) & Benthivore & 12 \\
\hline Stenotomus chrysops (Linnaeus, 1766) & Benthivore & 13 \\
\hline Glyptocephalus cynoglossus (Linnaeus, 1758) & Benthivore & 14 \\
\hline Anarhichas lupus Linnaeus, 1758 & Benthivore & 15 \\
\hline Brosme brosme (Ascanius, 1772) & Benthivore & 16 \\
\hline Prionotus carolinus (Linnaeus, 1771) & Benthivore & 17 \\
\hline Helicolenus dactylopterus (Delaroche, 1809) & Benthivore & 18 \\
\hline Triglops murrayi Günther, 1888 & Benthivore & 19 \\
\hline Citharichthys arctifrons Goode, 1880 & Benthivore & 20 \\
\hline Centropristis striata (Linnaeus, 1758) & Benthivore & 21 \\
\hline Enchelyopus cimbrius (Linnaeus, 1766) & Benthivore & 22 \\
\hline Aspidophoroides monopterygius (Bloch, 1786) & Benthivore & 23 \\
\hline Squalus acanthias Linnaeus, 1758 & Piscivore & 1 \\
\hline Leucoraja ocellata (Mitchill, 1815) & Piscivore & 2 \\
\hline Gadus morhua Linnaeus, 1758 & Piscivore & 3 \\
\hline Merluccius bilinearis (Mitchill, 1814) & Piscivore & 4 \\
\hline Pollachius virens (Linnaeus, 1758) & Piscivore & 5 \\
\hline Lophius americanus Valenciennes in Cuvier and Valenciennes, 1837 & Piscivore & 6 \\
\hline
\end{tabular}


Sea raven

White hake

Summer flounder

Acadian redfish

Atlantic halibut

Smooth skate

Spotted hake

Offshore hake

Windowpane

Butterfish

Atlantic herring

Atlantic mackerel

Alewife

Northern sand lance

American shad

Longfin hake
Hemitripterus americanus (Gmelin, 1789)

Urophycis tenuis (Mitchill, 1814)

Paralichthys dentatus (Linnaeus, 1766)

Sebastes fasciatus Storer, 1854

Hippoglossus hippoglossus (Linnaeus, 1758)

Malacoraja senta (Garman, 1885)

Urophycis regia (Walbaum, 1792)

Merluccius albidus (Mitchill, 1818)

Scophthalmus aquosus (Mitchill, 1815)

Peprilus triacanthus (Peck, 1804)

Clupea harengus Linnaeus, 1758

Scomber scombrus Linnaeus, 1758

Alosa pseudoharengus (Wilson, 1811)

Ammodytes dubius Reinhardt, 1837

Alosa sapidissima (Wilson, 1811)

Phycis chesteri Goode and Bean, 1878
Piscivore

Piscivore

Piscivore

Piscivore

Piscivore

Piscivore

Piscivore

Piscivore

Planktivore

Planktivore

Planktivore

Planktivore

Planktivore

Planktivore

Planktivore

Planktivore
8

9

\subsection{Bay of Biscay}

\begin{tabular}{|c|c|c|c|}
\hline Common name & Latin name & Functional group & Rank \\
\hline Poor cod & Trisopterus minutus (Linnaeus, 1758) & Benthivore & 1 \\
\hline Bib & Trisopterus luscus (Linnaeus, 1758) & Benthivore & 2 \\
\hline Small-spotted catshark & Scyliorhinus canicula (Linnaeus, 1758) & Benthivore & 3 \\
\hline Thinlipped mullet & Liza ramado (Risso, 1810) & Benthivore & 4 \\
\hline Dragonet & Callionymus lyra Linnaeus, 1758 & Benthivore & 5 \\
\hline Red gurnard & Chelidonichthys cuculus (Linnaeus, 1758) & Benthivore & 6 \\
\hline Greater weever & Trachinus draco Linnaeus, 1758 & Benthivore & 7 \\
\hline Black seabream & Spondyliosoma cantharus (Linnaeus, 1758) & Benthivore & 8 \\
\hline Red mullet & Mullus surmuletus Linnaeus, 1758 & Benthivore & 9 \\
\hline Bogue & Boops boops (Linnaeus, 1758) & Benthivore & 10 \\
\hline Blackbelly rosefish & Helicolenus dactylopterus & Benthivore & 11 \\
\hline Common sole & Solea solea (Linnaeus, 1758) & Benthivore & 12 \\
\hline Greater forkbeard & Phycis blennoides (Brünnich, 1768) & Benthivore & 13 \\
\hline Grey gurnard & Eutrigla gurnardus (Linnaeus, 1758) & Benthivore & 14 \\
\hline Thickback sole & Microchirus variegatus (Donovan, 1808) & Benthivore & 15 \\
\hline Imperial scaldfish & Arnoglossus imperialis (Rafinesqe, 1810) & Benthivore & 16 \\
\hline Common dab & Limanda limanda (Linnaeus, 1758) & Benthivore & 17 \\
\hline
\end{tabular}




\begin{tabular}{|c|c|c|c|}
\hline Sand goby & Pomatoschistus minutus (Pallas, 1770) & Benthivore & 18 \\
\hline Softhead grenadier & Malacocephalus laevis (Lowe, 1843) & Benthivore & 19 \\
\hline Spotted dragonet & Callionymus maculatus Rafinesque, 1810 & Benthivore & 20 \\
\hline Longspine snipefish & Macroramphosus scolopax (Linnaeus, 1758) & Benthivore & 21 \\
\hline European hake & Merluccius merluccius (Linnaeus, 1758) & Piscivore & 1 \\
\hline European conger & Conger conger (Linnaeus, 1758) & Piscivore & 2 \\
\hline European whiting & Merlangius merlangus (Linnaeus, 1758) & Piscivore & 3 \\
\hline Anglerfish & Lophius piscatorius Linnaeus, 1758 & Piscivore & 4 \\
\hline European seabass & Dicentrarchus labrax (Linnaeus, 1758) & Piscivore & 5 \\
\hline Cuckoo ray & Leucoraja naevus (Müller and Henle, 1841) & Piscivore & 6 \\
\hline Thornback ray & Raja clavata Linnaeus, 1758 & Piscivore & 7 \\
\hline John dory & Zeus faber Linnaeus, 1758 & Piscivore & 8 \\
\hline Blackbellied angler & Lophius budegassa Spinola, 1807 & Piscivore & 9 \\
\hline Megrim & Lepidorhombus whiffiagonis (Walbaum, 1792) & Piscivore & 10 \\
\hline Blackmouth catshark & Galeus melastomus Rafinesque, 1810 & Piscivore & 11 \\
\hline European plaice & Pleuronectes platessa Linnaeus, 1758 & Piscivore & 12 \\
\hline Fourbeard rockling & Enchelyopus cimbrius & Piscivore & 13 \\
\hline Atlantic horse mackerel & Trachurus trachurus (Linnaeus, 1758) & Planktivore & 1 \\
\hline Atlantic mackerel & Scomber scombrus & Planktivore & 2 \\
\hline Blue whiting & Micromesistius poutassou (Risso, 1827) & Planktivore & 3 \\
\hline European anchovy & Engraulis encrasicolus (Linnaeus, 1758) & Planktivore & 4 \\
\hline European pilchard & Sardina pilchardus (Walbaum, 1792) & Planktivore & 5 \\
\hline Boarfish & Capros aper (Linnaeus, 1758) & Planktivore & 6 \\
\hline Mediterranean horse mackerel & Trachurus mediterraneus (Steindachner, 1868) & Planktivore & 7 \\
\hline European sprat & Sprattus sprattus sprattus (Linnaeus, 1758) & Planktivore & 8 \\
\hline Silver smelt & Argentina sphyraena Linnaeus, 1758 & Planktivore & 9 \\
\hline Atlantic argentine & Argentina silus (Ascanius, 1775) & Planktivore & 10 \\
\hline Lesser sand eel & Ammodytes tobianus Linnaeus, 1758 & Planktivore & 11 \\
\hline Silvery pout & Gadiculus argenteus Guichenot, 1850 & Planktivore & 12 \\
\hline Red bandfish & Cepola macrophthalma (Linnaeus, 1758) & Planktivore & 13 \\
\hline
\end{tabular}


4.9. North Sea

\begin{tabular}{|c|c|c|c|}
\hline Common name & Latin name & Functional group & Rank \\
\hline Common dab & Limanda limanda & Benthivore & 1 \\
\hline European plaice & Pleuronectes platessa & Benthivore & 2 \\
\hline American plaice & Hippoglossoides platessoides & Benthivore & 3 \\
\hline Lemon sole & Microstomus kitt (Walbam, 1792) & Benthivore & 4 \\
\hline Flounder & Platichthys flesus (Linnaeus, 1758) & Benthivore & 5 \\
\hline Witch flounder & Glyptocephalus cynoglossus & Benthivore & 6 \\
\hline Shorthorn sculpin & Myoxocephalus scorpius (Linnaeus, 1758) & Benthivore & 7 \\
\hline Red gurnard & Chelidonichthys cuculus & Benthivore & 8 \\
\hline Lesser weever & Echiichthys vipera (Cuvier, 1829) & Benthivore & 9 \\
\hline Dragonet & Callionymus lyra & Benthivore & 10 \\
\hline Common sole & Solea solea & Benthivore & 11 \\
\hline Solenette & Buglossidium luteum (Risso, 1810) & Benthivore & 12 \\
\hline Armed bullhead & Agonus cataphractus (Linnaeus, 1758) & Benthivore & 13 \\
\hline Blackbelly rosefish & Helicolenus dactylopterus ) & Benthivore & 14 \\
\hline Checker eelpout & Lycodes vahlii Reinhardt, 1831 & Benthivore & 15 \\
\hline Spotted dragonet & Callionymus maculatus & Benthivore & 16 \\
\hline Snake pipefish & Entelurus aequoreus (Linnaeus, 1758) & Benthivore & 17 \\
\hline Scaldfish & Arnoglossus laterna (Walbaum, 1792) & Benthivore & 18 \\
\hline Gobies & Pomatoschistus spp. & Benthivore & 19 \\
\hline Haddock & Melanogrammus aeglefinus & Piscivore & 1 \\
\hline European whiting & Merlangius merlangus & Piscivore & 2 \\
\hline Atlantic cod & Gadus morhua & Piscivore & 3 \\
\hline Grey gurnard & Eutrigla gurnardus & Piscivore & 4 \\
\hline Pollock & Pollachius virens & Piscivore & 5 \\
\hline Thorny skate & Amblyraja radiata & Piscivore & 6 \\
\hline Ling & Molva molva (Linnaeus, 1758) & Piscivore & 7 \\
\hline Anglerfish & Lophius piscatorius & Piscivore & 8 \\
\hline Thornback ray & Raja clavata & Piscivore & 9 \\
\hline Poor cod & Trisopterus minutus & Piscivore & 10 \\
\hline Small-spotted catshark & Scyliorhinus canicula & Piscivore & 11 \\
\hline Bib & Trisopterus luscus & Piscivore & 12 \\
\hline Cuckoo ray & Leucoraja naevus & Piscivore & 13 \\
\hline European hake & Merluccius merluccius & Piscivore & 14 \\
\hline Megrim & Lepidorhombus whiffiagonis & Piscivore & 15 \\
\hline
\end{tabular}




\begin{tabular}{llc}
\hline Fourbeard rockling & Enchelyopus cimbrius & Piscivore \\
Herring & Clupea harengus harengus Linnaeus, 1758 & Planktivore \\
Norway pout & Trisopterus esmarkii (Nilsson, 1855) & Planktivore \\
European sprat & Sprattus sprattus sprattus & Planktivore \\
Atlantic mackerel & Scomber scombrus & Planktivore \\
Atlantic horse mackerel & Trachurus trachurus & Planktivore \\
Silver smelt & Argentina sphyraena & Planktivore \\
Greater sand eels & Hyperoplus spp. & Planktivore \\
Blue whiting & Micromesistius poutassou & Planktivore \\
European anchovy & Engraulis encrasicolus & Planktivore \\
Sand lances & Ammodytes spp. & Planktivore \\
Atlantic argentine & Argentina silus & Planktivore \\
European pilchard & Sardina pilchardus & Planktivore \\
Silvery pout & Gadiculus argenteus & Planktivore \\
Pearlside & Maurolicus muelleri (Gmelin, 1789) & 10 \\
\hline
\end{tabular}


Appendix 2. Results of sensitivity analysis for smoother span

Number of agreements between survey-based biomass and mean weight time trends and model predictions (Spearman rank correlation test, $\alpha=0.1$ ), depending on the span used for the smoother.

\begin{tabular}{|c|c|c|c|c|c|c|}
\hline & \multicolumn{5}{|c|}{ Smoother span (yrs) } & \multirow[b]{2}{*}{ Number of predictions } \\
\hline & 7 & 10 & 15 & 20 & 30 & \\
\hline \multicolumn{7}{|l|}{ Georges Bank } \\
\hline All & 10 & 10 & 10 & 11 & 14 & 19 \\
\hline Benthivores & 6 & 6 & 6 & 5 & 5 & 8 \\
\hline Piscivores & 2 & 2 & 2 & 2 & 3 & 4 \\
\hline Planktivores & 2 & 2 & 2 & 4 & 6 & 7 \\
\hline \multicolumn{7}{|l|}{ Bay of Biscay } \\
\hline All & 2 & 3 & 5 & 6 & 6 & 8 \\
\hline Benthivores & 1 & 1 & 2 & 2 & 2 & 2 \\
\hline Piscivores & 1 & 2 & 2 & 3 & 3 & 3 \\
\hline $\begin{array}{l}\text { Planktivores } \\
\text { North Sea }\end{array}$ & 0 & 0 & 1 & 1 & 1 & 3 \\
\hline All & 7 & 8 & 10 & 9 & 7 & 14 \\
\hline Benthivores & 1 & 1 & 2 & 2 & 2 & 4 \\
\hline Piscivores & 3 & 4 & 5 & 4 & 2 & 5 \\
\hline Planktivores & 3 & 3 & 3 & 3 & 3 & 5 \\
\hline
\end{tabular}


Appendix 3. Correlation matrices of common trends within functional groups Significant correlations $(\alpha=0.1)$ are marked by asterisks. Group", smoothed trend of total biomass in the functional group. Trend $1, \ldots 6$, common trends estimated by dynamic factor analysis. Negative correlations between common trends reveal compensation.

Georges Bank

\begin{tabular}{|c|c|c|c|c|c|c|}
\hline Benthivores & Group & Trend 1 & Trend 2 & Trend 3 & Trend 4 & Trend 5 \\
\hline Trend 1 & 0.05 & 1 & & & & \\
\hline Trend 2 & $0.88^{*}$ & $-0.25^{\star}$ & 1 & & & \\
\hline Trend 3 & 0.15 & -0.2 & 0.3 & 1 & & \\
\hline Trend 4 & 0.19 & 0.13 & 0 & 0.12 & 1 & \\
\hline Trend 5 & $-0.44^{*}$ & $-0.38^{*}$ & -0.09 & $0.38^{*}$ & -0.14 & 1 \\
\hline Trend 6 & 0.24 & $-0.62^{*}$ & $0.53^{*}$ & 0.24 & -0.1 & $0.25^{*}$ \\
\hline Piscivores & Group & Trend 1 & Trend 2 & & & \\
\hline Trend 1 & $-0.66^{*}$ & 1 & & & & \\
\hline Trend 2 & $0.68 *$ & $-0.51 *$ & 1 & & & \\
\hline Trend 3 & $0.78^{*}$ & $-0.53^{*}$ & 0.17 & & & \\
\hline Planktivores & Group & Trend 1 & Trend 2 & & & \\
\hline Trend 1 & $-0.61 *$ & 1 & & & & \\
\hline Trend 2 & $-0.51 *$ & $0.67 *$ & 1 & & & \\
\hline Trend 3 & $0.82^{*}$ & $-0.35^{*}$ & $-0.32^{*}$ & & & \\
\hline \multicolumn{7}{|l|}{ Bay of Biscay } \\
\hline Benthivores & Group & Trend 1 & & & & \\
\hline Trend 1 & $0.90^{*}$ & 1 & & & & \\
\hline Trend 2 & $0.39 *$ & 0.29 & & & & \\
\hline Piscivores & Group & Trend 1 & & & & \\
\hline Trend 1 & $0.90^{*}$ & 1 & & & & \\
\hline Trend 2 & 0.16 & -0.16 & & & & \\
\hline Planktivores & Group & Trend 1 & & & & \\
\hline Trend 1 & -0.34 & 1 & & & & \\
\hline Trend 2 & $0.79^{*}$ & $-0.44^{*}$ & & & & \\
\hline \multicolumn{7}{|l|}{ North Sea } \\
\hline Benthivores & Group & Trend 1 & Trend 2 & & & \\
\hline Trend 1 & $0.81^{*}$ & 1 & & & & \\
\hline Trend 2 & $0.49 *$ & $0.37 *$ & 1 & & & \\
\hline Trend 3 & -0.02 & -0.28 & -0.12 & & & \\
\hline Piscivores & group & Trend 1 & Trend 2 & Trend 3 & & \\
\hline Trend 1 & $-0.87^{*}$ & 1 & & & & \\
\hline Trend 2 & $0.61 *$ & $-0.64 *$ & 1 & & & \\
\hline Trend 3 & -0.23 & 0.3 & $-0.44 *$ & 1 & & \\
\hline Trend 4 & $0.65^{*}$ & $-0.39^{*}$ & $0.37^{*}$ & $-0.4^{*}$ & & \\
\hline
\end{tabular}




\section{Tables}

Table 1. Details about the bottom-trawl surveys used to calculate fish community metrics.

\begin{tabular}{|c|c|c|c|}
\hline \multirow{5}{*}{$\frac{\text { Community }}{\text { Name of survey }}$} & Georges Bank & Bay of Biscay & North Sea \\
\hline & Northeast & Evaluation & International Bottom \\
\hline & Fisheries Science & ressources & Trawl Survey \\
\hline & Bottom & Halieutiques & \\
\hline & Trawl Survey & l'Ouest Europe & \\
\hline Season & Fall & Quarter 4 & Quarter 1 \\
\hline Time series used in this study & 1963-2007 & 1987-2010 & 1983--2009 \\
\hline Gear & \#36 Yankee trawl & $\mathrm{GOV}^{\mathrm{a}}$ trawl $36 / 47$ & $\mathrm{GOV}^{\mathrm{a}}$ trawl \\
\hline Cod-end mesh size $(\mathrm{cm})$ & 1.25 & 2 & 2 \\
\hline Vertical opening $(\mathrm{m})$ & 3.2 & 4.1 & 4.1 \\
\hline Footrope length (m) & 24.4 & 47 & 47 \\
\hline Footrope equipment & Rubber rollers & Rubber discs & Rubber discs \\
\hline Headrope equipment & 36 floats & 126 floats & Floats + exocet kite \\
\hline Area covered $\left(\mathrm{km}^{2}\right)$ & 43,000 & 75,575 & 575,300 \\
\hline Survey reference & Azarovitz 1981 & ICES 1991 & ICES 1996 \\
\hline
\end{tabular}

${ }^{\mathrm{a}}$ Grande ouverture verticale. 
Table 2. Decadal levels of fishing pressure and primary production, and the predicted consequences of changes in pressure levels on decadal trends in functional-group metrics from perturbation analysis of the model in Figure 1 for Georges Bank, the Bay of Biscay, and the North Sea.

$\mathrm{B}$, predicted changes in biomass; $\mathrm{E}$, changes in life expectancy; +, increase; -, decrease. Blank cells indicate predictions with a low certainty probability in any of the model variants. Predicted trends that were actually found in the functional groups (one-tailed test for monotonic trend in the smooth time series in Figure 3, $\alpha=0.1$ ) are marked by asterisks.

\begin{tabular}{|c|c|c|c|c|c|c|c|c|c|c|c|c|}
\hline \multirow[b]{2}{*}{ Pressures } & \multicolumn{5}{|c|}{ Georges Bank } & \multicolumn{3}{|c|}{ Bay of Biscay } & \multicolumn{4}{|c|}{ North Sea } \\
\hline & 1960s & $1970 s$ & 1980s & 1990s & $2000 s$ & $1980 s$ & 1990s & $2000 s$ & 1970s & 1980s & 1990s & $2000 s$ \\
\hline Demersal fishery & High & Medium & High & Low & Low & High & High & Low & High & Low & Low & Low \\
\hline Pelagic fishery & Medium & High & Low & Low & Low & High & High & Low & High & Low & Low & Low \\
\hline Primary production & Low & High & High & High & High & Low & High & High & Low & Low & High & Low \\
\hline \multicolumn{13}{|c|}{ Functional groups: predicted consequences } \\
\hline Benthivores & & $B+{ }^{*} \mathrm{E}-{ }^{*}$ & $B-{ }^{*} E+$ & $\mathrm{B}+{ }^{*} \mathrm{E}-$ & $\mathrm{B}+{ }^{*} \mathrm{E}-{ }^{*}$ & & $B+{ }^{*} \mathrm{E}-{ }^{*}$ & & & & $\mathrm{~B}+\mathrm{E}-{ }^{*}$ & $B-E+*$ \\
\hline Piscivores & & $\mathrm{B}+*$ & B- & $\mathrm{B}+$ & $B+^{*}$ & & $B+E-*$ & $\mathrm{~B}+{ }^{*}$ & & $\mathrm{~B}+*$ & $\mathrm{~B}+{ }^{*} \mathrm{E}-{ }^{*}$ & $B-{ }^{*} E+*$ \\
\hline Planktivores & & E- & $B+E+$ & $\mathrm{B}-\mathrm{E}-$ & $B-{ }^{*} E-{ }^{*}$ & & $B-E-*$ & $\mathrm{~B}-$ & & $\mathrm{B}-$ & $\mathrm{B}+{ }^{*} \mathrm{E}-{ }^{*}$ & $\mathrm{~B}-{ }^{*} \mathrm{E}+$ \\
\hline
\end{tabular}


Table 3. Summary of results: comparison of observed functional group biomass and mean average weight changes with model predictions based on observed decadal pressure changes (see Table 2), dynamic factor analysis results for species compensation or synchrony within functional groups, species richness $(R)$, and average Simpson reciprocal evenness within functional groups (SRE). A, agreement for all decadal periods; D, difference for all periods; $M$, agreement depended on period; NA, no model predictions; $C$, compensation (at least two dynamic factor analysis common trends negatively correlated); $\mathrm{S}$, synchrony (one common trend shared by $>0.5$ species in the functional group); I, independent.

\begin{tabular}{|c|c|c|c|c|c|}
\hline Ecosystem/functional group & Biomass & Mean weight & Compensation & $\mathrm{R}$ & SRE \\
\hline \multicolumn{6}{|l|}{ Georges Bank } \\
\hline Benthivores & A & A & C & 23 & 0.21 \\
\hline Piscivores & $\mathrm{M}$ & NA & C & 14 & 0.20 \\
\hline Planktivores & M & $\mathrm{M}$ & C & 8 & 0.33 \\
\hline \multicolumn{6}{|l|}{ Bay of Biscay } \\
\hline Benthivores & A & A & I & 21 & 0.25 \\
\hline Piscivores & M & A & S & 13 & 0.59 \\
\hline Planktivores & $\mathrm{D}$ & $A$ & C & 13 & 0.33 \\
\hline \multicolumn{6}{|l|}{ North Sea } \\
\hline Benthivores & D & A & S & 19 & 0.09 \\
\hline Piscivores & $A$ & $A$ & C & 16 & 0.19 \\
\hline Planktivores & M & M & I & 14 & 0.14 \\
\hline
\end{tabular}

\section{Figures}

Figure 1. A simplified dynamic model of an exploited shelf-fish community. System variables are functional-group biomass (circles) and fleet capacity, e.g., number of vessels or total power (squares). Arrows represent positive links, small circles negative links. Solid lines represent established links; dotted lines may be weak links. Triangles show the pressure changes of which the consequences were analyzed. Ppis, pelagic piscivores; Plv, pelagic planktivores; Plkt, plankton; PPP, pelagic primary production; Dpis, demersal piscivores; Btv, demersal benthivores; Bthos, benthos; BPP, benthic primary production. Dem fleet, demersal fleet; Pel fleet, Pelagic fleet; Inv fleet, Invertebrate fleet.

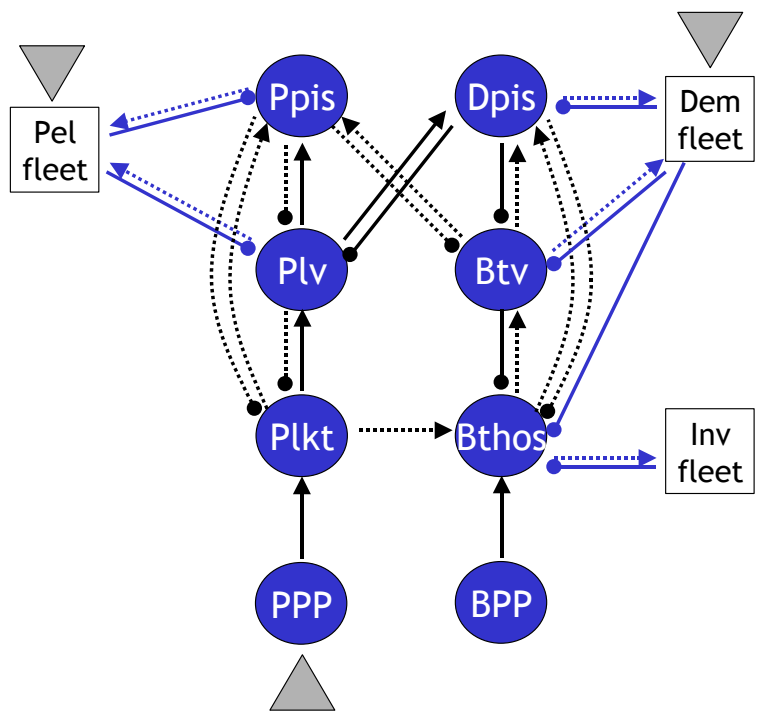


Figure 2. Time series of landings $(A, C, E)$ and an index of exploitation $(B, D, F)$ by functional group on Georges Bank (A-B), in the Bay of Biscay (C-D), and in the North Sea $(\mathrm{E}-\mathrm{F})$. Right axes on the right panels are for planktivores.
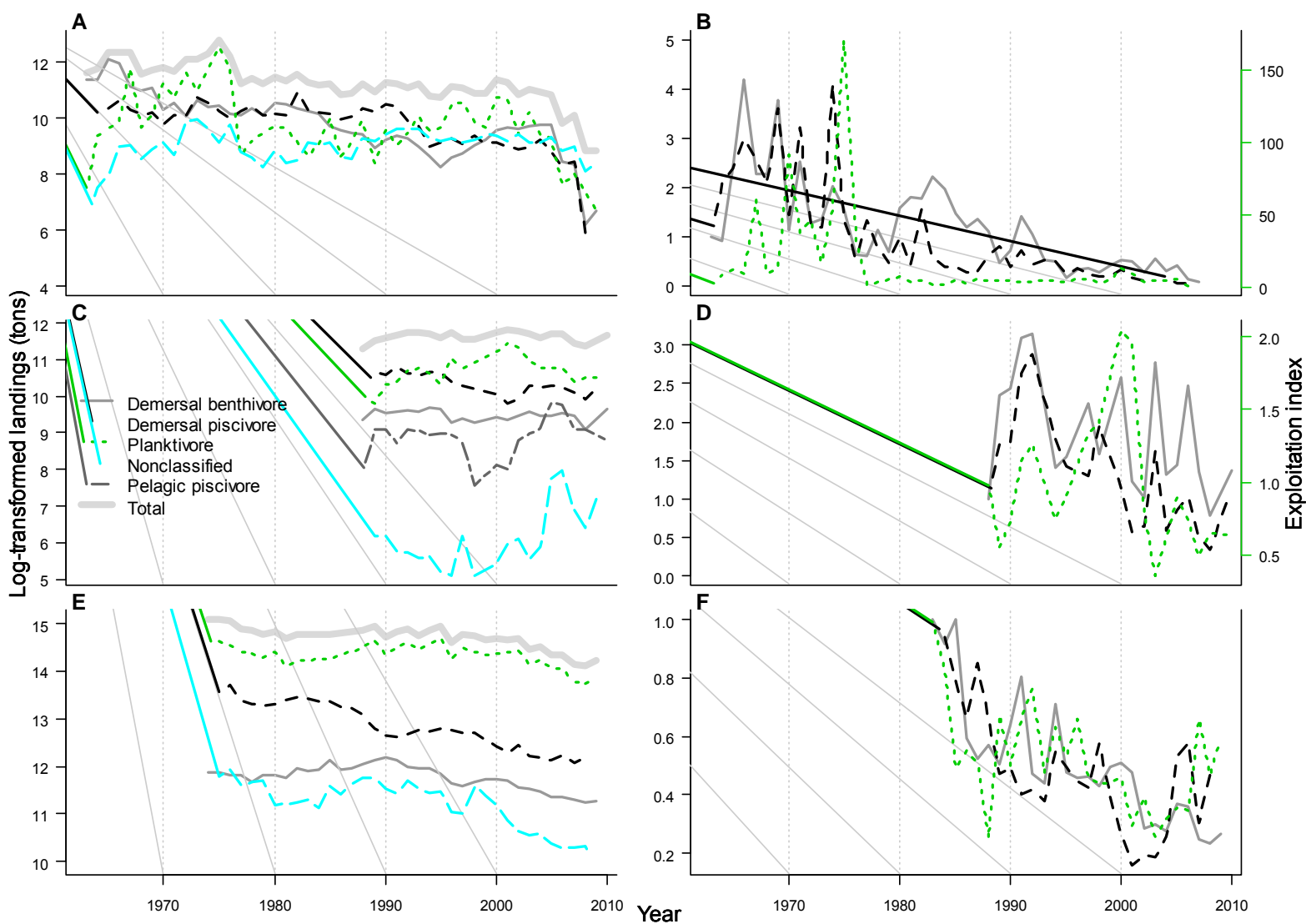
Figure 3. Biomass and mean average weight of functional groups on Georges Bank (top two rows), in the Bay of Biscay (middle two rows), and in the North Sea (bottom two rows). Heavy lines are a lowess smoother fit (span $=15 \mathrm{yrs}$ ). $\mathrm{t}$, metric tons.
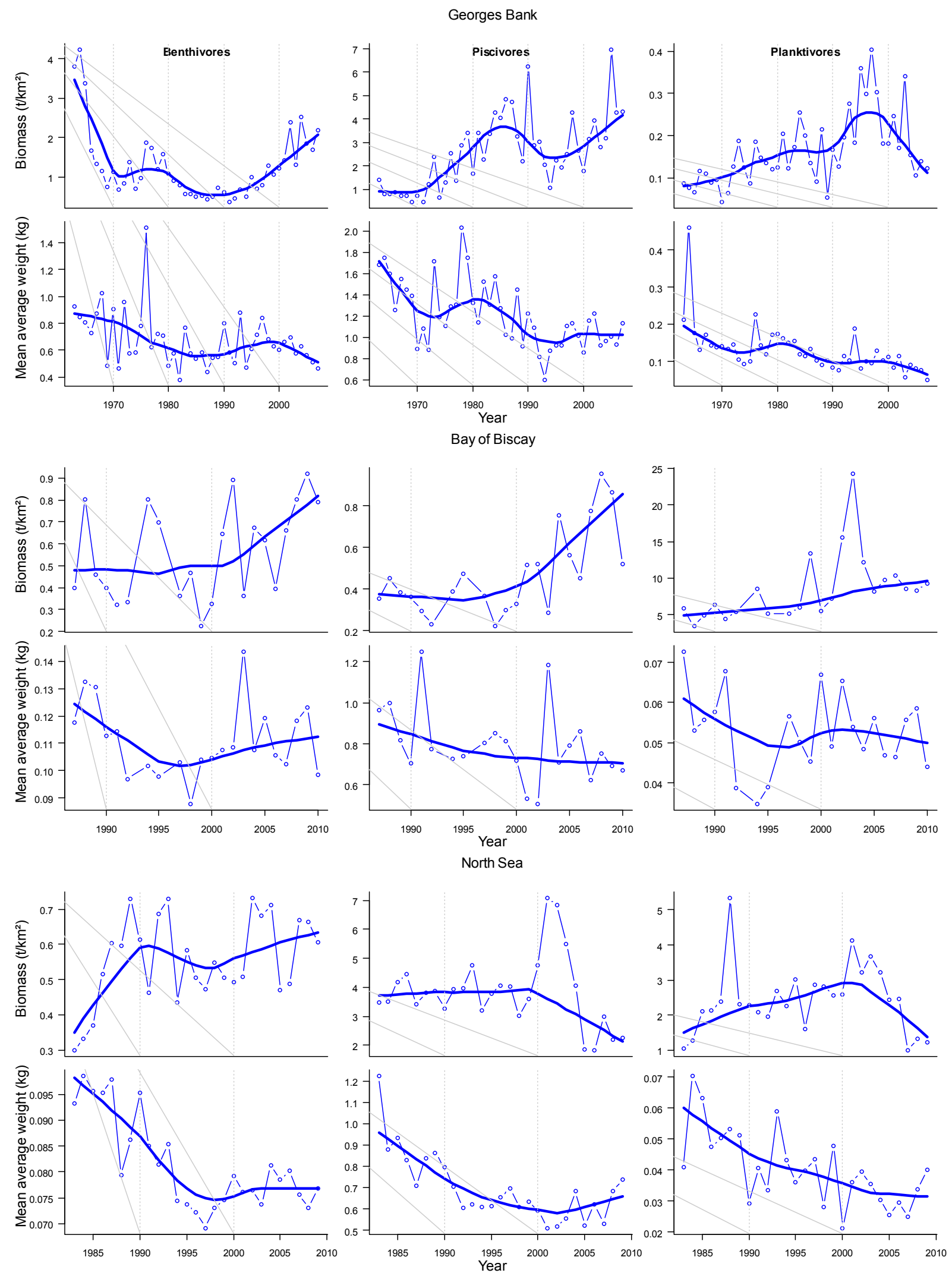
Figure 4. Left: Common trends in Georges Bank functional groups. The solid gray line is the smoothed series of group biomass (same as Figure 3); each of the other lines is a fitted trend common to several species within the group. Right: the species loadings on the common trends in each functional-group biomass. Only loadings larger than 0.1 are shown (Benthivores: Trend 1, species 2, 3, 6, 7, 9, 11, 12, 14, 15, 17, 18, 20, 22; Trend 2, species 1, 4, 8, 9, 10, 12, 19; Trend 3, species 3, 4, 5, 9, 11, 12, 13, 17, 18, 19, 21, 23; Trend 4, species 2, 4, 5, 10, 17, 19, 20; Trend 5 , species $7,9,10,11,14,16,19$; Trend 6 , species 1 , $3,4,5,7,11,14,17,19,20,22$, 23. Piscivores: Trend 1 , species $2,3,5,6,8,11,12,13$, 14; Trend 2, species 1, 7, 9; Trend 3, species 1, 2, 4, 8. Planktivores: Trend 1, species 5, 6; Trend 2, species 5, 7, 8; Trend 3, species 1, 2, 3, 4). Species are ranked in order of decreasing biomass; the gray line is the cumulative biomass (scale 0-1 on the horizontal axis). See species names and ranks in Appendix 1.
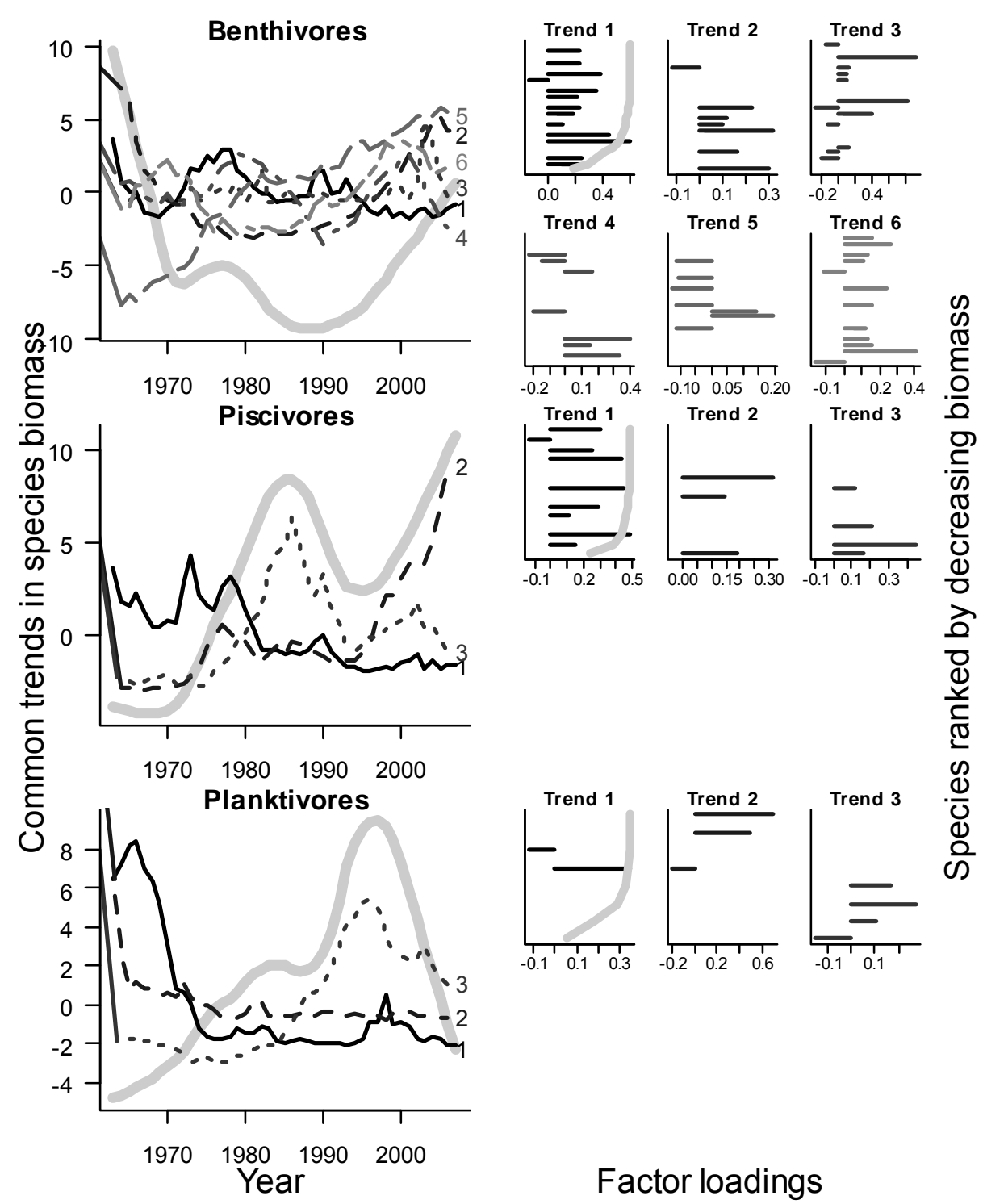

Factor loadings 
Figure 5. Species composition (biomass proportion) of each functional group on Georges Bank (top), in the Bay of Biscay (middle), and in the North Sea (bottom). Species are plotted from the bottom to the top by decreasing order of average biomass (see species names and ranks in Appendix 1).
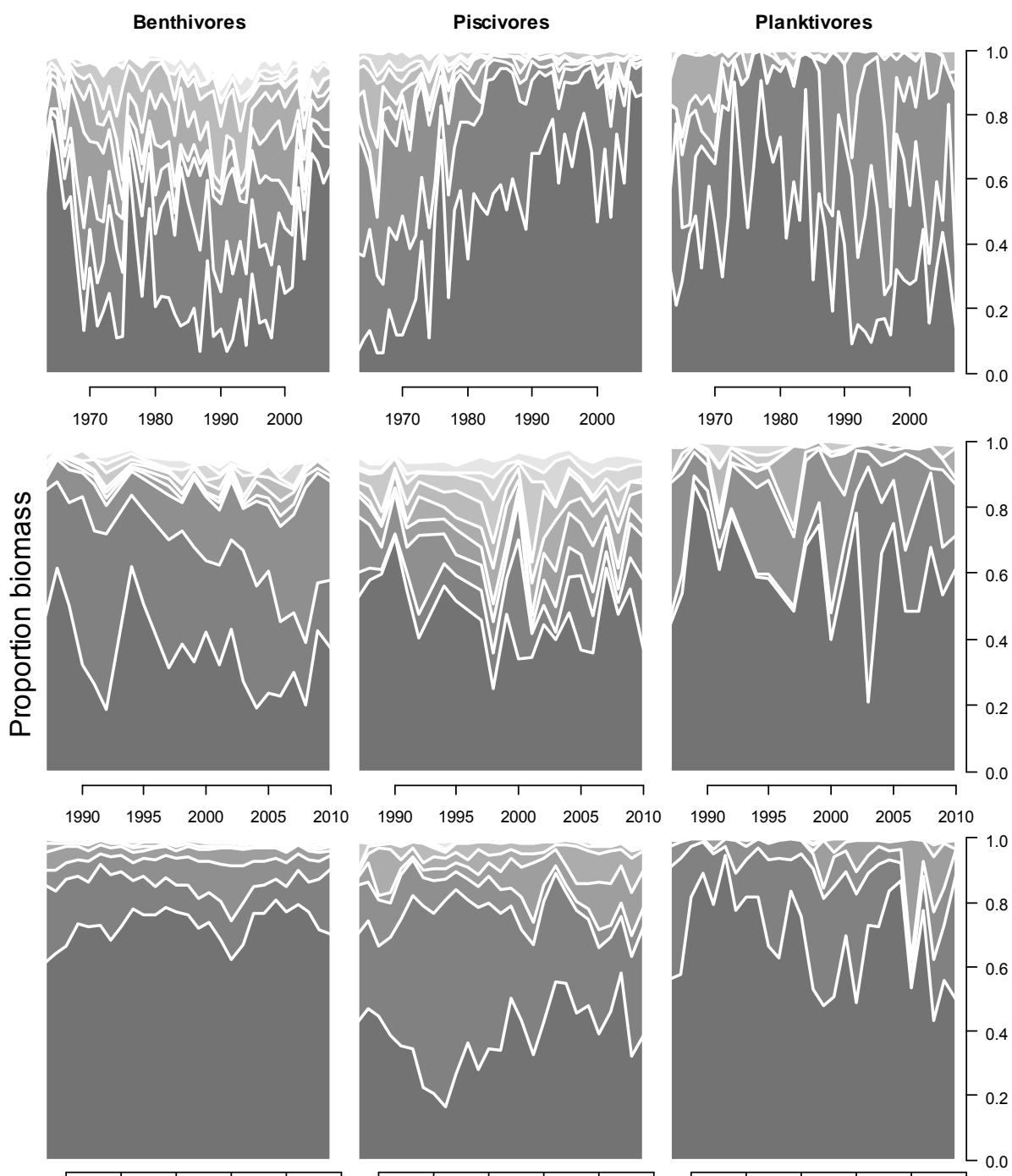

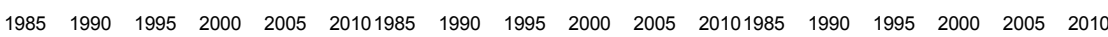
Year 
Figure 6. Left: Common trends in the Bay of Biscay functional groups. The gray line is the smoothed series of group biomass; each of the other lines is a fitted trend common to the species within the group. Right: the species loadings on the common trends in each functional-group biomass. Only loadings larger than 0.1 are shown (Benthivores: Trend 1, species 3, 6, 7, 10, 11, 13, 14, 16, 18; Trend 2, species 8, 12, 15, 17, 18, 19, 20, 21. Piscivores: Trend 1, species 1, 2, 3, 4, 5, 6, 8, 9, 10, 11, 12; Trend 2, species 1, 3, 6, 10, 12, 13. Planktivores: Trend 1, species 4, 5, 6, 7, 8, 9, 10, 11, 12; Trend 2, species 1, 2, 3, 5, 6, $8,9,10,12,13)$. Species are ranked in order of decreasing biomass; the gray line is the cumulative biomass (scale $0-1$ on the horizontal axis). See species names and ranks in Appendix 1.
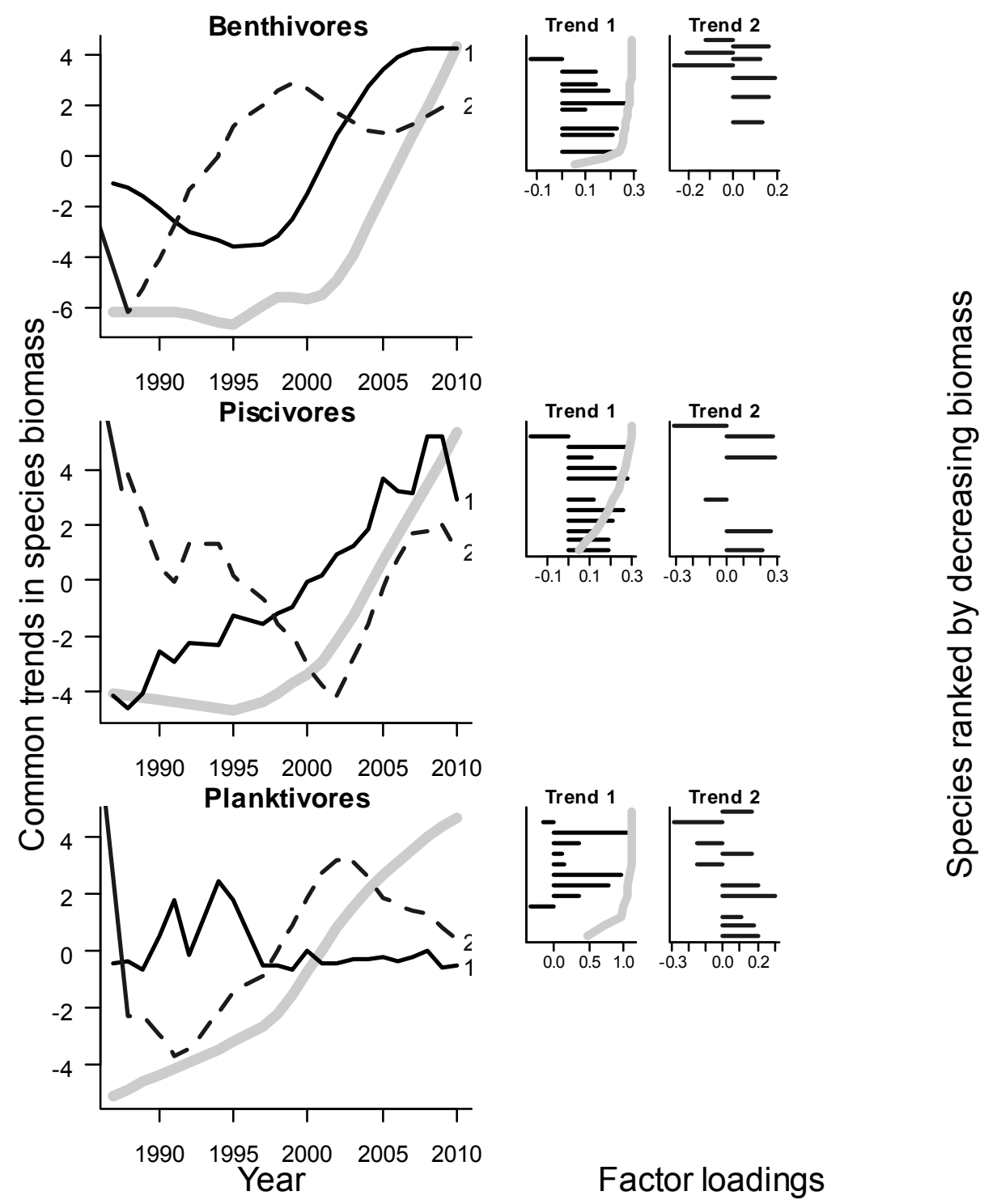

Factor loadings 
Figure 7. Left: Common trends in the North Sea functional groups. The gray line is the smoothed series of group biomass; each of the other lines is a fitted trend common to the species within the group. Right: the species loadings on the common trends in each functional-group biomass. Only loadings larger than 0.1 are shown (Benthivores: Trend 1 , species $1,2,3,4,6,7,8,9,10,11,12,13,14,15,16,18,19$; Trend 2, species 5, 6, 8, 9, 12 , 16, 17, 18; Trend 3, species 2, 3, 4, 5, 6, 9, 12, 14, 16, 17, 19. Piscivores: Trend 1, species $6,8,9,10,11,12,14,15$; Trend 2, species 1, 2, 6, 7, 9, 10, 11, 12, 13, 16; Trend 3, species $1,2,4,5,8,10,11,13,14$; Trend 4, species $3,4,7,11,12$, 16. Planktivores: Trend 1, species $2,3,4,5,6,10,13,14$.). Species are ranked in order of decreasing biomass; the gray line is the cumulative biomass (scale $0-1$ on the horizontal axis). See species names and ranks in Appendix 1.
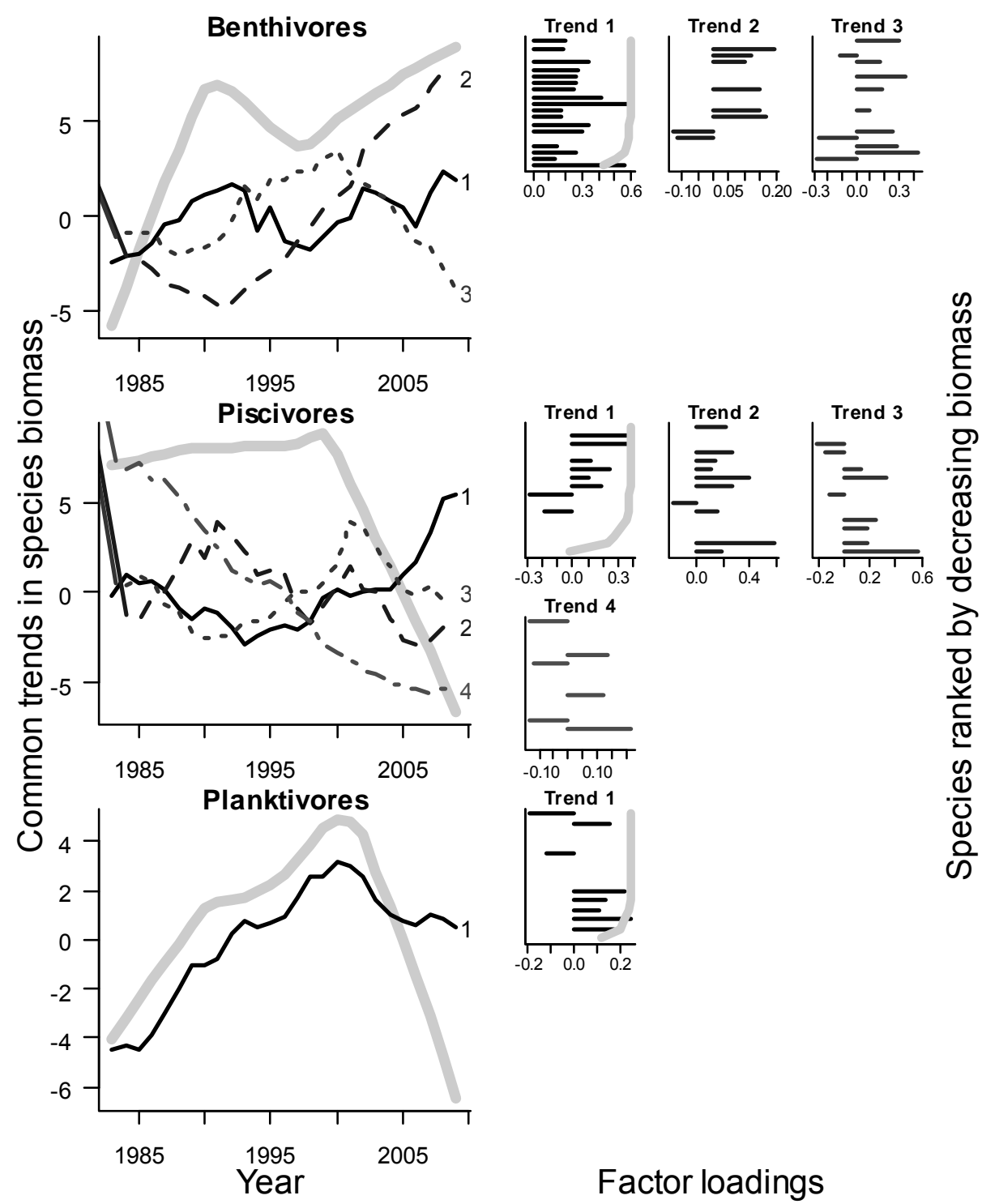

Factor loadings 